\title{
El género Krusa (Opiliones: Sclerosomatidae: Gagrellinae) en México
}

\author{
The genus Krusa (Opiliones: Sclerosomatidae: Gagrellinae) in Mexico \\ Lizbeth Gaona-Escamilla $^{\mathrm{a}}$, Oscar F. Francke ${ }^{\mathrm{b}}$ y Javier Ponce-Saavedra ${ }^{\mathrm{a}, *}$ \\ ${ }^{a}$ Laboratorio de Entomología Biól. Sócrates Cisneros Paz, Facultad de Biología, Universidad Michoacana de San Nicolás de Hidalgo, Edificio B4, 2. ${ }^{\circ}$ Piso, \\ Ciudad Universitaria, 58030, Morelia, Michoacán, México \\ ${ }^{\mathrm{b}}$ Colección Nacional de Arácnidos, Departamento de Zoología, Instituto de Biología, Universidad Nacional Autónoma de México, Apartado postal 70-153, 04510, \\ Ciudad de México, México
}

Recibido el 6 de enero de 2016; aceptado el 16 de junio de 2016

Disponible en Internet el 22 de noviembre de 2016

\begin{abstract}
Resumen
Se presenta la revisión taxonómica del género Krusa Goodnight y Goodnight, 1947, el cual actualmente incluye 6 especies endémicas de México. Debido a que K. annulata Goodnight y Goodnight, 1945; K. flava Goodnight y Goodnight, 1946; K. metallica Goodnight y Goodnight, 1946; K. stellata Goodnight y Goodnight, 1946 y K. tuberculata Goodnight y Goodnight, 1946 fueron descritas previo a la publicación de la descripción del género y de la especie tipo, K. mexicana Goodnight y Goodnight, 1947, el uso del nombre genérico se considera como nomen nudum de acuerdo con el Código Internacional de Nomenclatura Zoológica; sin embargo, los nombres específicos son válidos aunque hayan sido publicados en combinación con un nombre genérico válido o no disponible (Código Internacional de Nomenclatura Zoológica, Art. 11) y conservan la autoría y fechas correspondientes. Krusa flava y K. metallica se mantienen como nominales y distintas a las del género Krusa. El género es diagnosticado con base en caracteres morfológicos externos y genitales masculinos y femeninos, y se redescriben las especies mencionadas además de describir a $K$. hidalguensis sp. nov. Se discute la problemática taxonómica del grupo, la exclusión de K. flava y K. metallica del género, así como la coherencia de nuestros resultados comparados con trabajos moleculares previos. Se presenta una clave dicotómica para la determinación específica. Como consecuencia de este trabajo, se propone la resurrección del género Krusella Roewer, 1953 de Venezuela.
\end{abstract}

(C) 2016 Universidad Nacional Autónoma de México, Instituto de Biología. Este es un artículo Open Access bajo la licencia CC BY-NC-ND (http://creativecommons.org/licenses/by-nc-nd/4.0/).

Palabras clave: Sistemática; Taxonomía; Nueva especie; Nomen nudum

\begin{abstract}
Taxonomic revision of genus Krusa Goodnight and Goodnight, 1947 is presented, which currently includes 6 species endemic to Mexico. As K. annulata Goodnight and Goodnight, 1945, K. flava Goodnight and Goodnight, 1946, K. metallica Goodnight and Goodnight, 1946, K. stellata Goodnight and Goodnight, 1947 and K. tuberculata Goodnight and Goodnight, 1946 were described prior to the publication of the description of the genus and the type species, K. mexicana Goodnight and Goodnight, 1947, the use of the generic name must be considered as nomen nudum according to the International Code of Zoological Nomenclature; however, the specific names are valid even if published in combination with a generic name that is not valid or unavailable (International Code of Zoological Nomenclature, Art. 11), and thus they retain the authorship and respective dates of publication. The aforementioned species are redescribed, and K. hidalguensis sp. nov. is described. Krusa flava and $K$. metallica remain as nominal species and do not belong in the genus Krusa. The genus is diagnosed based on external and male and female genital characters. Our results are congruent with previous molecular studies. A dichotomous key for the identification of species of Krusa is included. The revision leads us to resurrect the genus Krusella Roewer, 1953 from Venezuela.
\end{abstract}

(C) 2016 Universidad Nacional Autónoma de México, Instituto de Biología. This is an open access article under the CC BY-NC-ND license (http://creativecommons.org/licenses/by-nc-nd/4.0/).

Keywords: Systematics; Taxonomy; New species; Nomen nudum

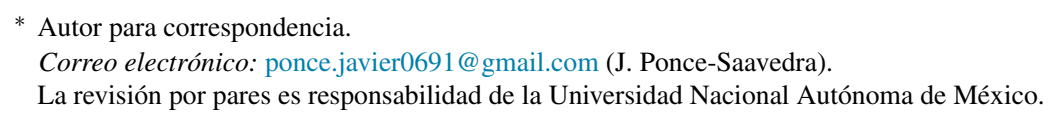




\section{Introducción}

La opiliofauna de México está compuesta por 4 subórdenes, 10 familias y 245 especies (Cruz-López, 2013; Cruz-López y Francke, 2012, 2013a,b, 2015; Cruz-López y Ubick, 2015; Giribet, 2011; Groh y Giribet, 2015; Hedin, Tsurusaky, MacíasOrdoñez y Shultz, 2012; Kury y Cokendolpher, 2000; PérezGonzález, 2006; Shear, 2004, 2006, 2010). A nivel mundial la familia Sclerosomatidae es la que presenta mayor riqueza dentro de la superfamilia Phalangioidea, con 135 géneros y 1,242 especies (Hedin et al., 2012). En México esta familia está representada por 78 especies agrupadas en las subfamilias Gagrellinae y Leiobuninae (Kury y Cokendolpher, 2000). La subfamilia Gagrellinae (fig. 1) representa gran parte de la fauna tropical y subtropical del suborden Eupnoi con 127 géneros y más de 800 especies (Taylor, 2009). En México se registran 7 géneros y 37 especies (Kury y Cokendolpher, 2000). Los primeros trabajos sobre la subfamilia Gagrellinae comienzan indirectamente con Pocock (1903), quien describió el género Prionostemma y la especie $P$. scintillans para Guatemala, siendo posteriormente Roewer (1923) quien la registró para México. PickardCambridge (1905), describió 4 especies más de este género. Posteriormente, Roewer (1910) describió el género Geaya y en 1953 elaboró una clave dicotómica de los géneros de Gagrellinae. Mello-Leitão (1933) describió el género Parageaya. Posteriormente, Goodnight y Goodnight $(1945,1946,1947)$ describieron 21 especies, lo que representa el 56\% de todas las especies conocidas de esta subfamilia para México. Cokendolpher (1981) hizo la revisión del género Trachyrhinus Weed 1892 y describió a T. rectipalpus de Coahuila y Tamaulipas.

En México, el género Krusa Goodnight y Goodnight, 1947 actualmente está conformado por 6 especies, las cuales en nuestra opinión tienen los siguientes problemas nomenclaturales: a) la descripción de $K$. annulata Goodnight y Goodnight fue publicada en 1945, 2 años antes que la descripción del género y la correcta designación de su especie tipo; $b$ ) las descripciones de $K$. flava Goodnight y Goodnight, K. metallica Goodnight y Goodnight, K. stellata Goodnight y Goodnight y K. tuberculata Goodnight y Goodnight fueron publicadas en 1946, un año antes de la descripción del género y $c$ ) en 1947 se publica la descripción de Krusa Goodnight y Goodnight con K. mexicana Goodnight y Goodnight, 1947 como especie tipo por monotipia. Como el nombre genérico no estuvo disponible hasta 1947, de acuerdo con el Código Internacional de Nomenclatura Zoológica en los artículos 13, 50 y 21, los usos previos a 1947 deben considerarse como nomina nuda; sin embargo, las 5 especies descritas antes de esa fecha son válidas de acuerdo con el artículo 11 del Código.

De acuerdo con Goodnight y Goodnight (1947), el género se caracteriza por el dorso sin espinas, oculario con pequeñas espinas sobre cada carena, fórmula nodular: 0-1-0-0 y coxas con filas de gránulos tripunteados en los márgenes laterales. Hedin et al. (2012) con base en un estudio molecular utilizando 4 genes nucleares y 2 segmentos mitocondriales, agrupan las especies de Krusa en 2 clados diferentes: a) K. annulata, $K$. mexicana y $K$. stellata en los Gagrellinae del Nuevo Mundo y b) $K$. flava y $K$. metallica en el clado II de México (Hedin et al., 2012: figs. 2 y 3). Con esto los autores hipotetizan que el género es polifilético, y las especies necesitan ser redescritas utilizando caracteres diagnósticos morfológicos que incluyan imágenes adecuadas de la morfología genital y de los patrones de coloración, caracteres considerados actualmente de importancia taxonómica en el suborden (Tourinho y Kury, 2001, 2003).
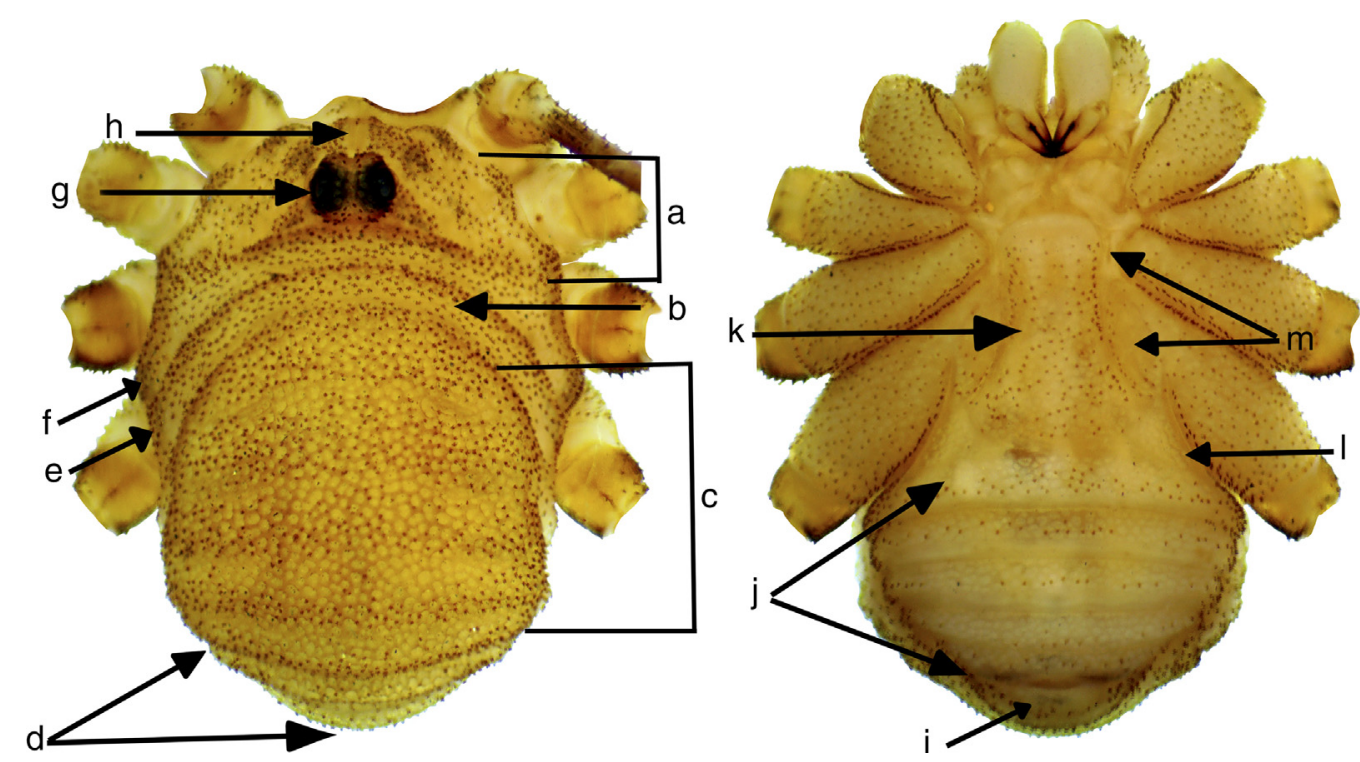

Figura 1. Caracteres morfológicos de gagrelínidos: izquierda, superficie dorsal: (a) cefalotórax, (b) segundo terguito prosomático, (c) scutum, (d) terguitos libres, (e) ELL T6, (f) ELL T5, (g) oculario y (h) lamelas supraquelicerales; derecha, superficie ventral: (i) opérculo anal, (j) esternitos del IX al XIV, (k) opérculo genital, (1) ELL E8 y (m) arculi genitales. 


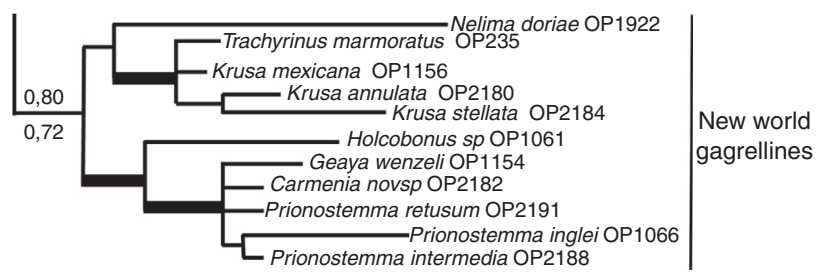

Figura 2. Clado tomado del trabajo de Hedin et al., 2012, donde las especies de Krusa se encuentran ubicadas en los gagrelínidos del Nuevo Mundo.
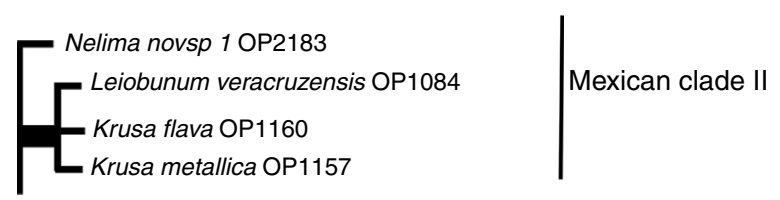

Figura 3. Clado tomado del trabajo de Hedin et al., 2012, donde algunas especies de Krusa se encuentran ubicadas en el clado mexicano II.

\section{Materiales y métodos}

Se revisó material de Krusa y de especímenes indeterminados de Sclerosomatidae de las siguientes colecciones: Colección Nacional de Arácnidos (CNAN) del Instituto de Biología de la Universidad Nacional Autónoma de México (UNAM) y de la Colección del Laboratorio de Entomología «Biól. Sócrates Cisneros Paz» de la Facultad de Biología de la Universidad Michoacana de San Nicolás de Hidalgo (CAFBUM). Para la observación de los ejemplares se utilizó un microscopio estereoscópico marca Zeiss modelo Stemi DV4. Las fotografías fueron tomadas con una cámara UCMOS0300KPA para microscopio AmScope y procesadas en el programa Combine ZP (Hadley, 2010). Las fotos fueron editadas en Photoshop ${ }^{\circledR}$ CS5 para fines de dar mejor contraste y prepararlas para impresión. Para las descripciones se siguió la nomenclatura de Rodríguez, Townsend y Proud (2014) y modificaciones de la nomenclatura de Tourinho y Kury (2001), como se aprecia en la figura 3. La morfología genital incluye: stylus, glande, porción alada y eje. Las medidas se tomaron con un vernier marca Stainless Hardened con una precisión de $0.01 \mathrm{~mm}$ y se presentan en $\mathrm{mm}$. Las medidas de los pedipalpos se presentan de la siguiente forma: trocánter/fémur/patela/tibia /tarso /total. Se elaboró un mapa con la distribución conocida de las especies del género Krusa mediante el software Maptool GMT v3.4 (2015). Además se revisaron ejemplares de Geaya Roewer, 1910, Leiobunum C.L. Koch 1839, Prionostemma Pocock, 1903 y Trachyrhinus Weed 1892.

Krusa Goodnight y Goodnight, 1947.

Krusa Goodnight y Goodnight, 1945, 1946, nomen nudum.

Krusa Goodnight y Goodnight, 1947: 55; Roewer, 1953: 182; Ringuelet, 1954: 293; Kury y Cokendolpher, 2000: 152.
Sinonimias: el género Krusella Roewer (1953) tiene como especie tipo a Krusella pilipes de San José del Ávila, Venezuela. Ringuelet (1954) propuso a Krusella bajo sinonimia con Krusa basándose en la formula nodular 0-1-0-0, la cual es homoplástica en la subfamilia. Por ello, se rechaza la propuesta de Ringuelet y se resucita el nombre Krusella.

Especie tipo: Krusa mexicana Goodnight y Goodnight, 1947, por monotipia.

Diagnosis: los machos presentan tamaños entre 2.27 y 3.59 y las hembras de 2.41 a 4.92 . Oculario con una fila de espinas pequeñas sobre cada carena, en algunos casos se pueden encontrar en la parte media (figs. 4d, 5d, 6f, 7d, 8d, 9d, 10f, 11d, 12f, 13d); dorso rugoso con numerosas depresiones de diferentes tamaños (figs. 4j, 8h, 10j, 12i), en ocasiones estas depresiones pueden estar presentes en la parte ventral; coxas y opérculo genital ornamentadas con numerosos tubérculos puntiagudos dispersos. Cara mesal del fémur del pedipalpo con una hilera de espinas tanto en macho como hembras (figs. 4n, 61, 7h, 8m, 9h, 10p, 11g, 12n, 13h). Los nódulos de la pata II pueden variar entre 1 o 2 y se localizan en la parte media (figs. 6c, 8g). Pene alado, la parte alada es triangular, ángulo lateral de aproximadamente $85^{\circ}$ y el stylus recto (figs. 4l, 61). Ovipositor conformado por 19 a 21 segmentos, cada segmento presenta 4 sedas, 2 en la parte media y un par externo (figs. 5f, 11f).

Distribución: México: Colima, Guerrero, Hidalgo, Michoacán, Nayarit, Oaxaca y Veracruz.

Especies incluidas: K. stellata, K. tuberculata, K. annulata, $K$. mexicana y $K$. hidalguensis sp. nov.

Nomenclatura: de acuerdo con el artículo 13 del Código Internacional de Nomenclatura Zoológica 4.a. Ed. (2000) en su versión en español (2009), el género Krusa es válido debido a que es una obra publicada que cumple con lo establecido en el artículo 8 y que satisface los requisitos del artículo 11, ya que Goodnight y Goodnight (1947) publicaron la descripción del género, presentando una diagnosis válida y cumpliendo con la designación de una especie tipo. Con respecto a las especies publicadas antes de la descripción del género, de acuerdo con el artículo 21 en sus fracciones 21.2 y 21.5 , se debe considerar la fecha de publicación de los trabajos de Goodnight y Goodnight como correctas y en consecuencia el uso del nombre genérico para las especies $K$. annulata Goodnight y Goodnight, 1945, K. tuberculata Goodnight y Goodnight, 1946 y K. stellata Goodnight y Goodnight, 1946 se constituye en nomina nuda. El término nomen nudum hace referencia a un nombre que si se publicó después de 1930 no cumple todos los requisitos del artículo 13 del Código Internacional de Nomenclatura Zoológica; por lo que de acuerdo con el mismo artículo, el nombre puede estar disponible posteriormente para el mismo concepto o acto nomenclatural u otro distinto. En función de lo anterior, el nombre de las especies del género Krusa que se describieron en combinación con un nomen nudum mantendrán su nombre y la autoría y la fecha de publicación original. 
Clave dicotómica para la identificación de las especies del género.

1. Dorso (figs. 6a y 7a) y lamelas supraquelicerales (fig. 6g) cubiertas con espinas pentapunteadas; los dentículos de los márgenes posterior y anterior de las coxas se extienden hasta cerca de la base (figs. $6 \mathrm{~b}$ y $7 \mathrm{~b}$ ); vientre con espinas de 5 puntas en las partes laterales (figs. 6c y $7 \mathrm{c}$ )

1'. Dorso sin espinas pentapunteadas (figs. 4a, 5a, 8a, 9a, 10a, 11a, 12a, 13a), lamelas supraquelicerales ornamentadas con tubérculos pequeños, romos o sin ornamentación (figs. $6 \mathrm{~g}$ y 8k); los dentículos tripunteados de los márgenes posterior y anterior de las coxas en fila (figs. 4i, 8j, 10k, 12g); vientre sin espinas de 5

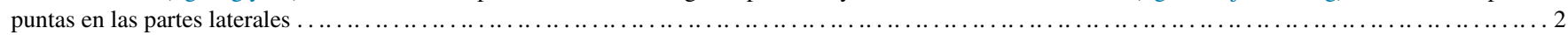

2. La parte ventral de la tibia del pedipalpo con una hilera de dentículos (figs. 4n y 10p), oculario sin espinas en la parte media (figs. 4d, 10f); coxas y opérculo genital con espinas y tubérculos que se encuentran dispersos (figs. 4g, 4h); lamelas supraquelicerales ornamentadas únicamente en la parte apical (figs. 4i, 12g); arculi genital II con dentículos en los márgenes laterales cercanos al opérculo genital (figs. 4h, 10i)

2'. La parte ventral de la tibia del pedipalpo sin hilera de dentículos (fig. 8n), oculario con espinas pequeñas en la parte media (fig. 8 d); coxas y opérculo genital con tubérculos grandes y conspicuos sobre toda la superficie (fig. 8b, 8c, 8i), lamelas supraquelicerales ornamentadas en la parte media y apical (fig. 8j); arculi genital II con dentículos con 3 puntas en los márgenes laterales cercanos al opérculo genital

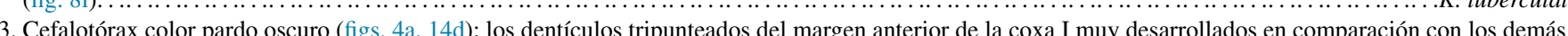
(fig. 4g); oculario con 5 espinas sobre cada carena (figs. 4d, 5d); fémur y patela de las patas con dentículos y en la tibia, desde la base hasta la mitad del segmento

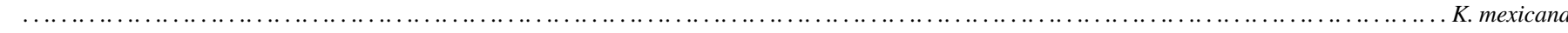

3'. Con manchas plateadas en el cefalotórax a los lados del oculario (figs. 14c y 14e); los dentículos tripunteados de los márgenes anteriores de la coxa I iguales de tamaño (fig. 101); oculario ornamentado con 5 o más espinas sobre cada carena (figs. 10f, 12f); patas con dentículos sobre toda la superficie del fémur, patela y tibia

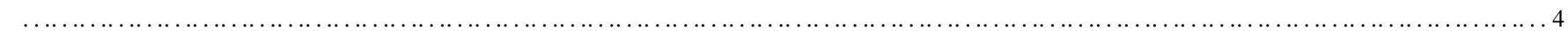

4. Cuerpo pardo claro, además de las manchas plateadas en el cefalotórax, presenta una marca triangular parda oscura que engloba el oculario (fig. 14c) el cual es pardo, con la base más clara y con espinas alrededor de cada carena; la parte apical de fémur y tibia de las patas con una franja blanquecina (figs. 10g, 10h); esta también se encuentra presente en la zona basal de tarso y metatarso; los dentículos de 3 puntas son del mismo tamaño en los márgenes anteriores de las coxas (fig. 101); tubérculos numerosos en las coxas y en los márgenes laterales y apical del opérculo genital en donde son más grandes (fig. 10i); quelíceros sin

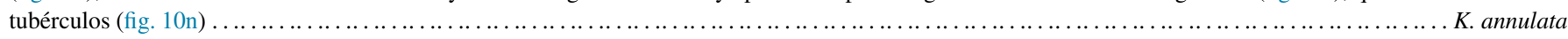

4'. Cuerpo de color pardo oscuro, cefalotórax con 2 manchas plateadas laterales (fig. 14e); el oculario negro con espinas grandes y conspicuas sobre cada carena y en la parte media presenta granulaciones (figs. 12f, 13d); sin franjas blanquecinas apicales en los segmentos de las patas; con dentículos tripunteados en los márgenes anteriores de las coxas, más desarrollados que los del margen posterior (fig. 12b, 12j); tubérculos y espinas dispersos en las coxas, márgenes laterales y margen anterior del opérculo genital (fig. 12h); quelíceros ornamentados en la superficie dorsal con algunos tubérculos y en la superficie mesal con gránulos con

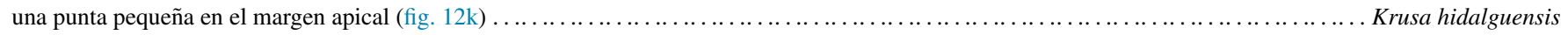

\section{Descripciones}

\section{Krusa mexicana Goodnight y Goodnight, 1947 (figs. 4-5, 14-15)}

Krusa mexicana Goodnight y Goodnight, 1947: 55; Roewer, 1953: 182; Kury y Cokendolpher, 2000:150; Hedin et al., 2012: 228.

Diagnosis: lamelas supraquelicerales bifurcadas (fig. 4j), los dentículos tripunteados del margen anterior de la coxa I muy desarrollados en comparación con los demás (fig. 4g); las ornamentaciones de las patas son dentículos pequeños que se encuentran en el fémur, patela y en la tibia desde la base hasta la mitad del segmento; oculario con 5 espinas sobre cada carena (figs. 4d, 5d); presenta una coloración negro brillante y una marca triangular pardo oscuro que engloba el oculario.

Redescripción: macho (afuera de la Cueva Ojo de Agua, municipio de Tlilapan, Veracruz). Longitud del cuerpo: 2.16, ancho 1.93, cefalotórax 1.03, scutum 1.09. Dorso: cefalotórax cubierto de depresiones, más grandes en los márgenes laterales (figs. 4a, 5a); oculario en la parte posterior, acanalado, restringido en la base y presenta una fila de 5 espinas sobre cada carena (figs. 4d, 5d); lamelas supraquelicerales bifurcadas (fig. 4j); segundo terguito prosomático, ELL T5 y ELL T6 con depresiones. Scutum, terguitos libres y opérculo anal cubiertos con sedas y depresiones más pequeñas que en el resto del cuerpo (figs. 4a, 4j). Vientre: cubierto de ligeras depresiones, esternitos con numerosas sedas, presentan algunos tubérculos; coxas con tubérculos y espinas (figs. 4b, 5b), además, presenta una hilera de dentículos de 3 puntas en los márgenes, más desarrollados en el margen anterior de la coxa I (fig. 4g) y ausentes en el margen posterior de la coxa III; opérculo genital con espinas principalmente en el margen anterior y algunas dispersas en el margen posterior, también presenta algunos dentículos en fila sobre los márgenes laterales (fig. 4h); arculi genitales I y II ornamentadas con sedas y en los márgenes laterales cerca del opérculo con una fila de dentículos (fig. 4h). Quelíceros: longitud 1.02. Con algunas sedas en la superficie dorsal siendo más numerosas cerca de los dedos. Basiquelicerito con una proyección en la parte ventral, el segundo segmento presenta sedas gruesas en la superficie mesal cerca de los dedos (figs. 4k, 5e) y también se encuentran algunas en la parte ectal. Pedipalpos: medidas. 0.21/0.67/0.32/0.43/0.82/2.45. Trocánter con dentículos pequeños en la superficie ventral y algunos en la dorsal; en el fémur los dentículos son más grandes y conspicuos en la zona ventral, donde se ubican dispersos en la parte basal y en la parte media forman 2 hileras divergentes lateralmente, en la superficie dorsal se aprecian 3 en la base, mientras que en la parte mesal se encuentra una hilera de 7 dentículos (fig. 4n); patela ornamentada con sedas y dentículos pequeños sobre toda la superficie; tibia con dentículos grandes igual que en el fémur, estos se encuentran dispersos en la zona ventral, además presenta dentículos más pequeños y sedas, excepto en la superficie mesal; tarso cubierto de sedas, en la parte distal se encuentran numerosas sedas gruesas agrupadas en la parte ventral cerca 

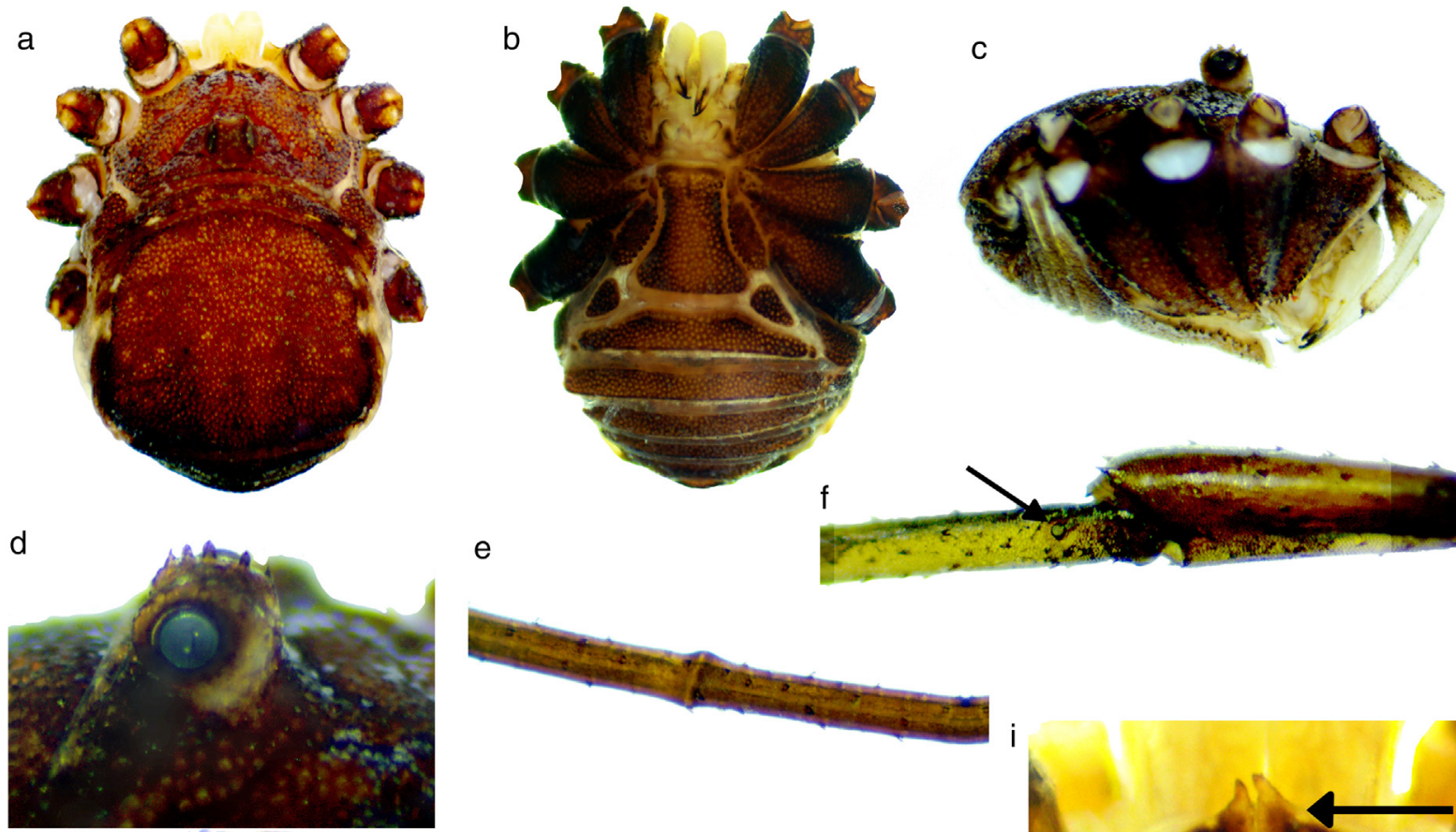

e
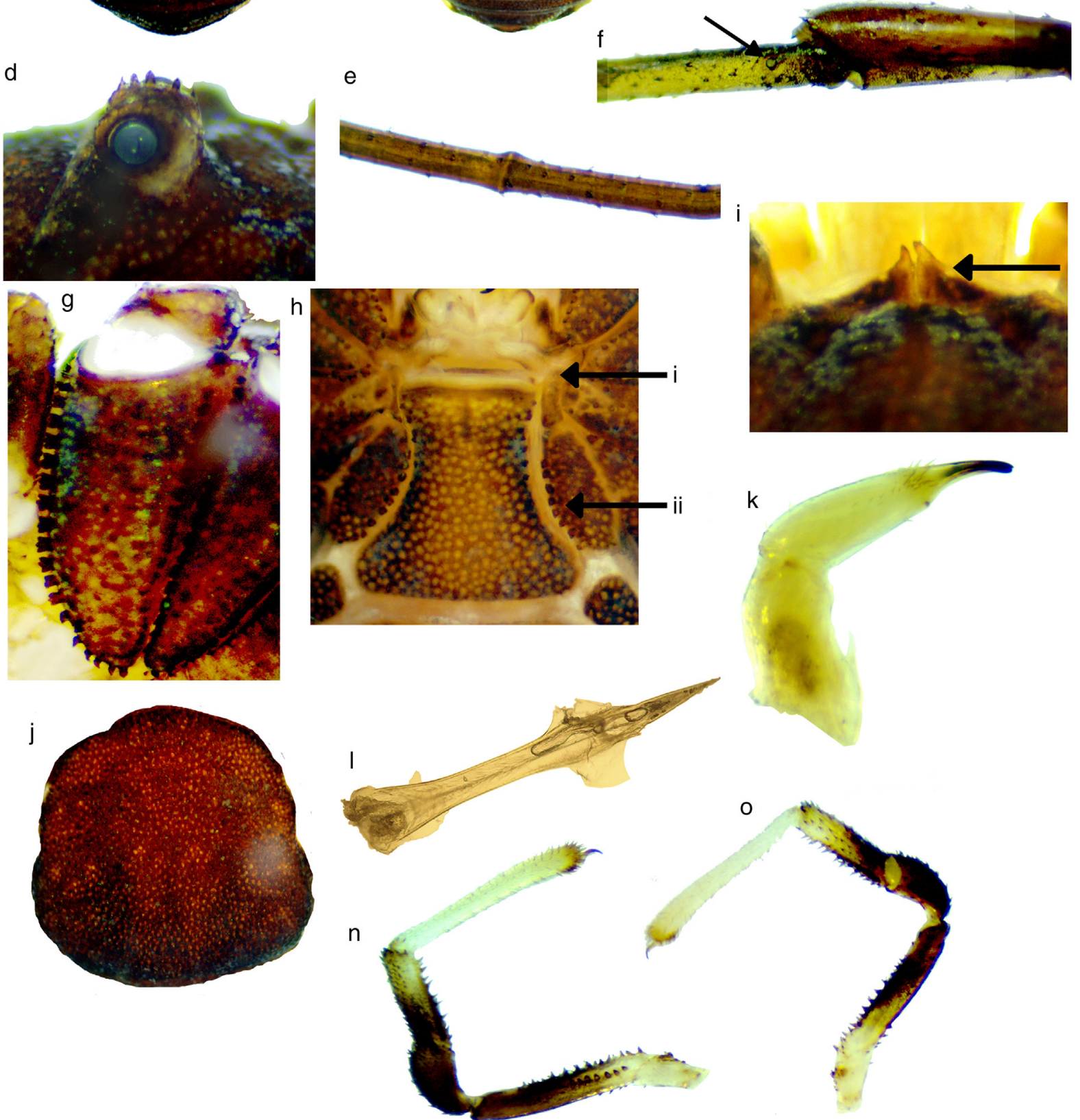

o

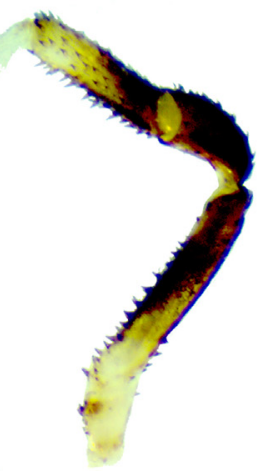

Figura 4. Krusa mexicana. Macho: (a) vista dorsal, (b) ventral, (c) lateral, (d) oculario, (e) nódulo femoral de la pata II, (f) estigma accesorio de la tibia II: la flecha indica su ubicación, (g) dentículos tripunteados del margen anterior de la coxa I, (h) opérculo genital y arculi genitales, la flecha superior muestra el arculi I y la inferior el II, (i) lamelas supraquelicerales, (j) depresiones del scutum, (k) quelícero, vista mesal, (l) pene vista ventral, (n) pedipalpo en vista mesal y (o) ectal. 

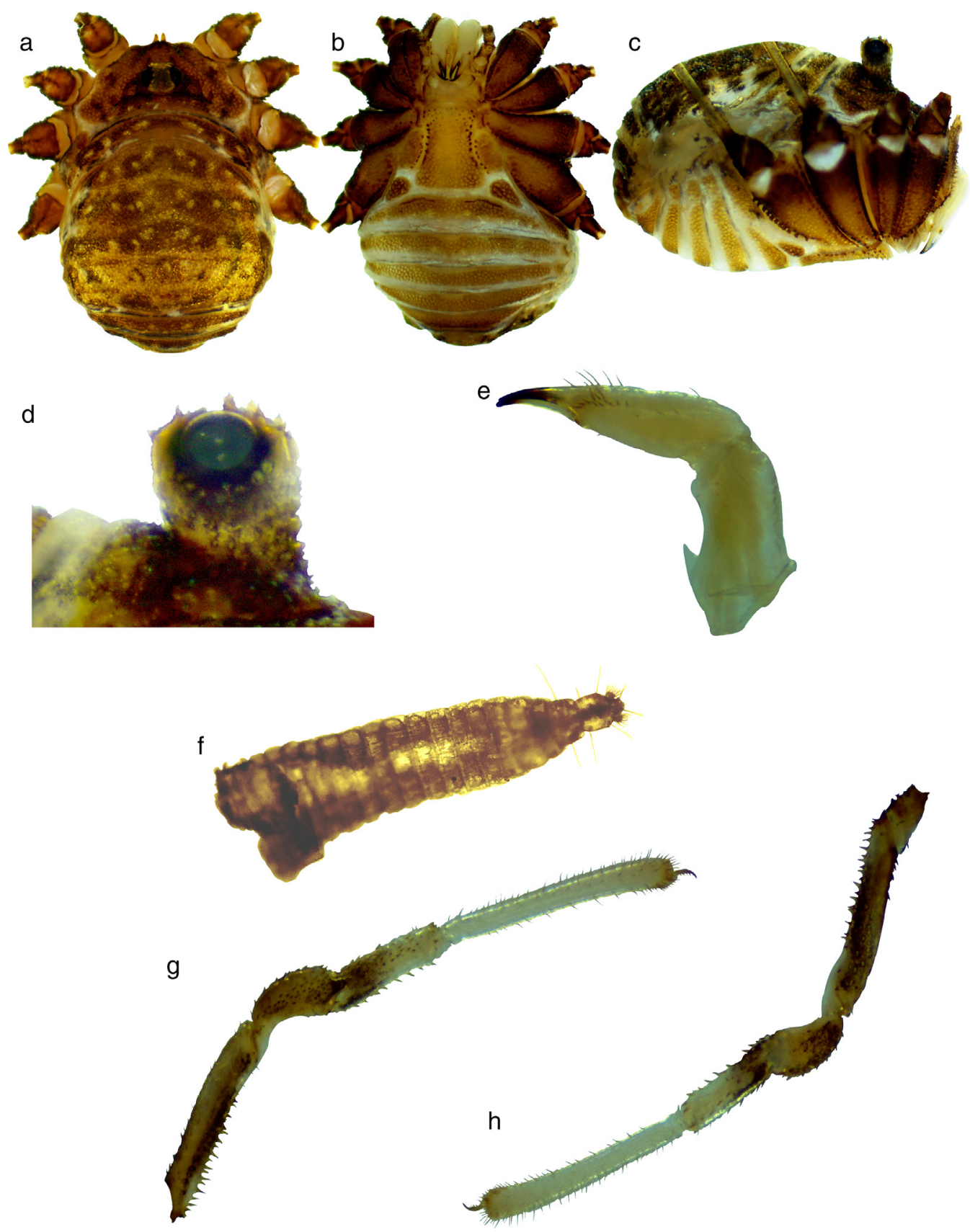

Figura 5. Krusa mexicana. Hembra: (a) vista dorsal, (b) ventral, (c) lateral, (d) oculario, (e) quelícero en vista mesal, (f) ovipositor, (g) pedipalpo en vista mesal y (h) ectal.

de la uña formando un mechón y también se pueden encontrar algunas dispersas (figs. 4n, 4o, 5g, 5h); uña con 4 dentículos en la parte media. Patas: medidas de los fémures, I: 9.38/II: 16.44/III: 9.40/IV: 12.47. Cubiertas con sedas; trocánter con algunos dentículos pequeños en los márgenes laterales, ausentes en la parte ventral y dorsal; fémur con dentículos pequeños dispersos sobre toda la superficie, en la patela se encuentran en filas longitudinales, aunque son escasos; en la tibia los dentículos se localizan sobre toda la superficie; tibias con estigmas accesorios (fig. 4f), presenta un nódulo en el fémur de la pata II (fig. 4e), metatarsos y tibia II con falsas articulaciones. Genitales masculinos: medida del pene: 1.52. Pene alado, estrecho de la parte media del tronco y más amplio de la parte basal y distal, la parte alada es triangular y el stylus es recto, el ángulo lateral es de aproximadamente $85^{\circ}$. La parte alada se presenta más hacia la parte apical (fig. 41). Coloración: dorso negro brillante, oculario negro (figs. $4 \mathrm{a}, 5 \mathrm{a}, 14 \mathrm{~d}$ ) y en la base pardo claro; vientre, opérculo genital y coxas negras, la articulación retrolateral de la coxa con el trocánter blanca; las piezas libres laterales de los esternitos IX al XIV y ELL E8 con manchas blancas; las patas son pardas, el trocánter y la base del fémur negras; pedipalpo: trocánter, fémur, patela y tibia negros, el tarso es de color amarillo, la tibia está moteada en la parte distal. Quelíceros amarillentos. 
a
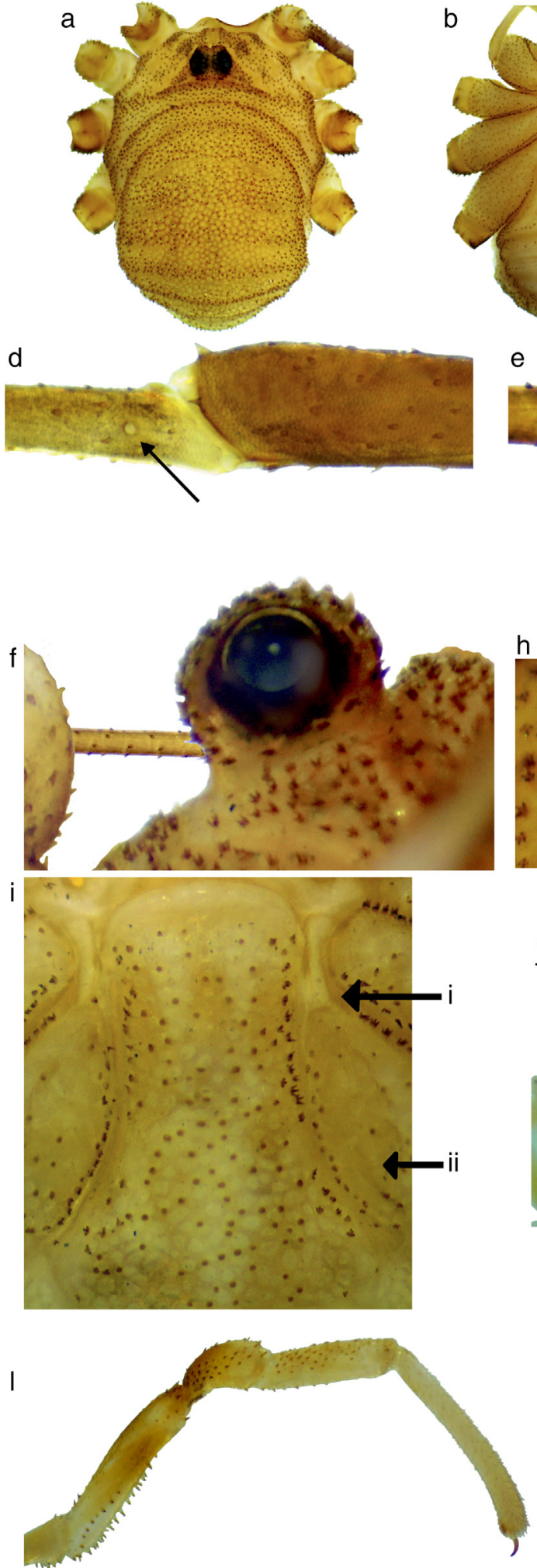

e

h

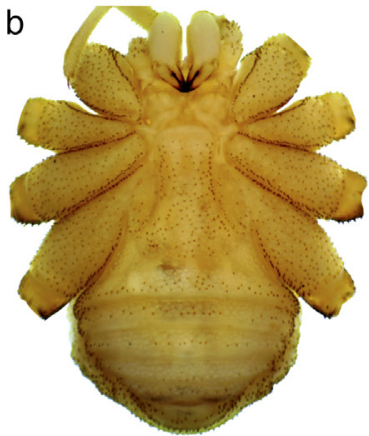

C
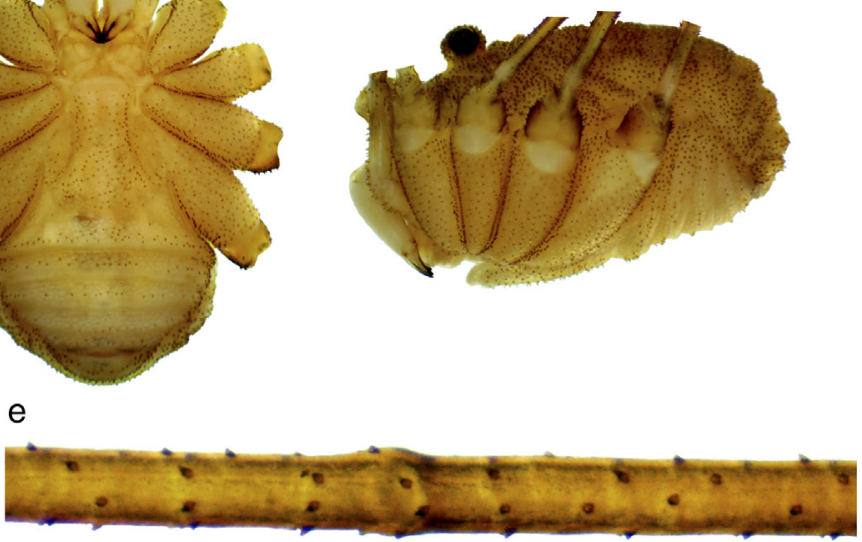

g
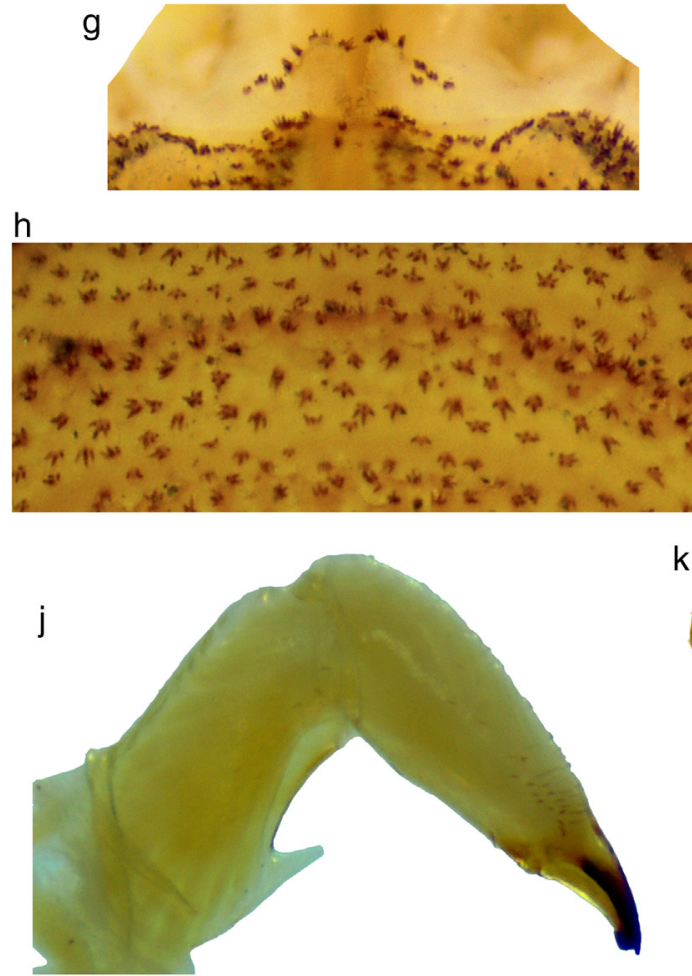

k

m

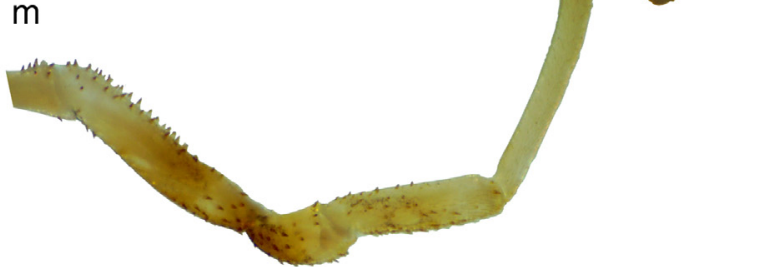

Figura 6. Krusa stellata. Macho: (a) vista dorsal, (b) ventral, (c) lateral, (d) estigma accesorio de la tibia, la flecha indica su ubicación, (e) nódulo femoral de la pata II, (f) oculario, (g) lamelas supraquelicerales, (h) depresiones del scutum, (i) opérculo genital y arculi genitales, la flecha superior muestra el arculi I y la inferior el II, (j) quelícero, en vista mesal, (k) pene, vista ventral, (l) pedipalpo en vista mesal y (m) ectal.

Hembras (afuera de la Cueva Ojo de Agua, municipio de Tlilapan, Veracruz): presentan los terguitos y esternitos más amplios (figs. 5a, 5b, 5c); dentículos de los márgenes laterales del opérculo genital más pequeños; coxas con menor número de espinas y más sedas; el segundo terguito prosomático es grande; son más notorias las piezas laterales de los esternitos IX al XIV y el ELL E8 (fig. 5b); las ornamentaciones en la superficie ventral del fémur del pedipalpo son menos densas 

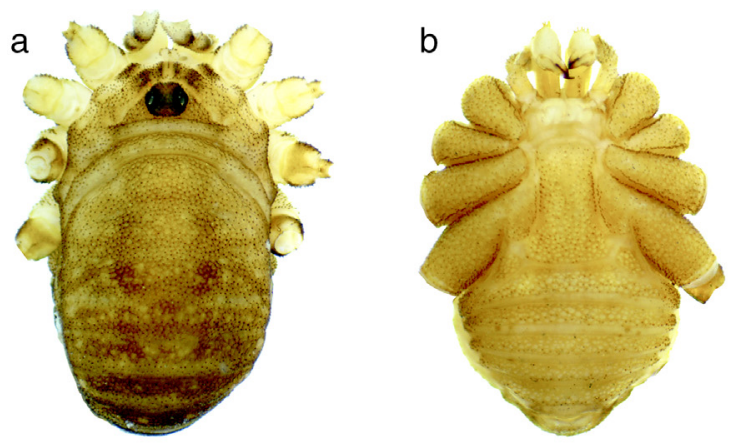

C
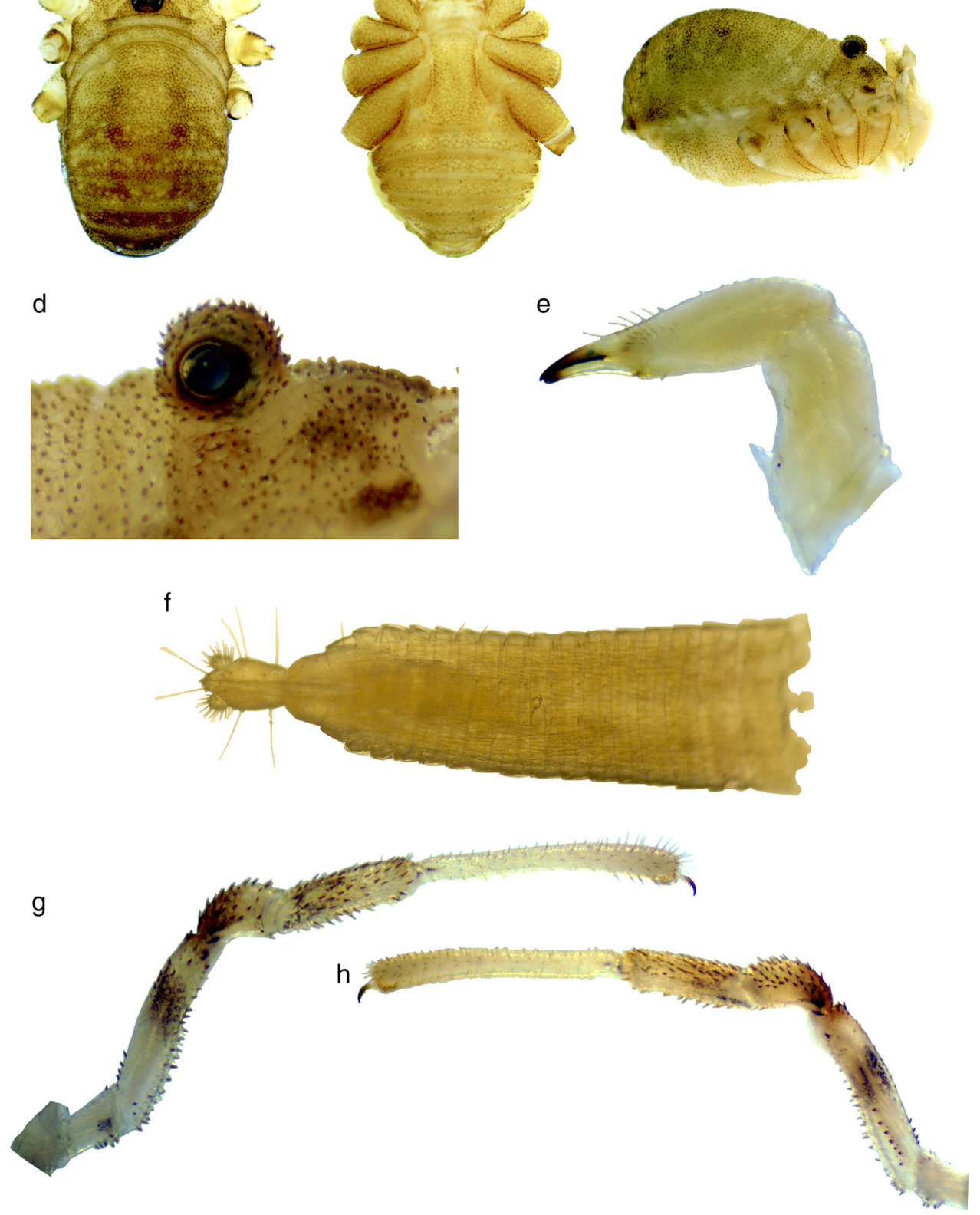

Figura 7. Krusa stellata. Hembra: (a) vista dorsal, (b) ventral, (c) lateral, (d) oculario, (e) quelícero en vista mesal, (f) ovipositor, (g) pedipalpo en vista ectal y (h) mesal.

y pequeñas (figs. $5 \mathrm{~g}, 5 \mathrm{~h}$ ). En las demás características son similares a los machos. El ovipositor es delgado y está formado por 20 segmentos; cada segmento posee 4 sedas, un par medio y un par externo (fig. 5f). Dimorfismo sexual: las hembras presentan el cuerpo redondeado y más grande (3.51 \pm 0.12 vs. $2.28 \pm 0.12$ ), oculario un poco más bajo que en los machos; los terguitos y esternitos son más amplios. Las patas son más largas en los machos. Variación: los dentículos del fémur pedipalpal pueden ser más pequeños en algunos ejemplares; la apófisis patelar presenta diferente tamaño (media $=0.027 \pm 0.01$ ); las espinas sobre cada carena son conspicuas en algunos ejemplares y en otros más pequeñas. Los ejemplares inmaduros son similares en cuanto al tamaño, el patrón de coloración varía con respecto a los adultos, ya que en estadios juveniles pueden presentar manchas pardas claras en el scutum y en ocasiones presentan puntos blanquecinos sobre toda la superficie del cuerpo. Los ejemplares machos presentan la siguiente variación en cuanto a sus medidas morfológicas: longitud del cuerpo $2.28 \pm 0.12$, ancho $1.99 \pm 0.04$, cefalotórax $1.04 \pm 0.03$, scutum $1.20 \pm 0.09$. Fémur I: $9.43 \pm 0.57$, II: $16.53 \pm 0.37$, III: $9.42 \pm 0.57$, IV: $12.14 \pm 0.36$. Longitud del pedipalpo: $0.2 \pm 0.01 / 0.71 \pm 0.03 / 0.32 \pm 0.02 / 0.42 \pm 0.01 / 0.84 \pm 0.01$.

Pene $1.57 \pm 0.03$. Las hembras presentan las siguientes medidas: longitud del cuerpo $3.51 \pm 0.12$, ancho $2.42 \pm 0.17$, cefalotórax $1.15 \pm 0.04, \quad$ scutum $1.30 \pm 0.06$. Fémur I: $8.83 \pm 0.62$, II: $15.15 \pm 1.35$, III: 

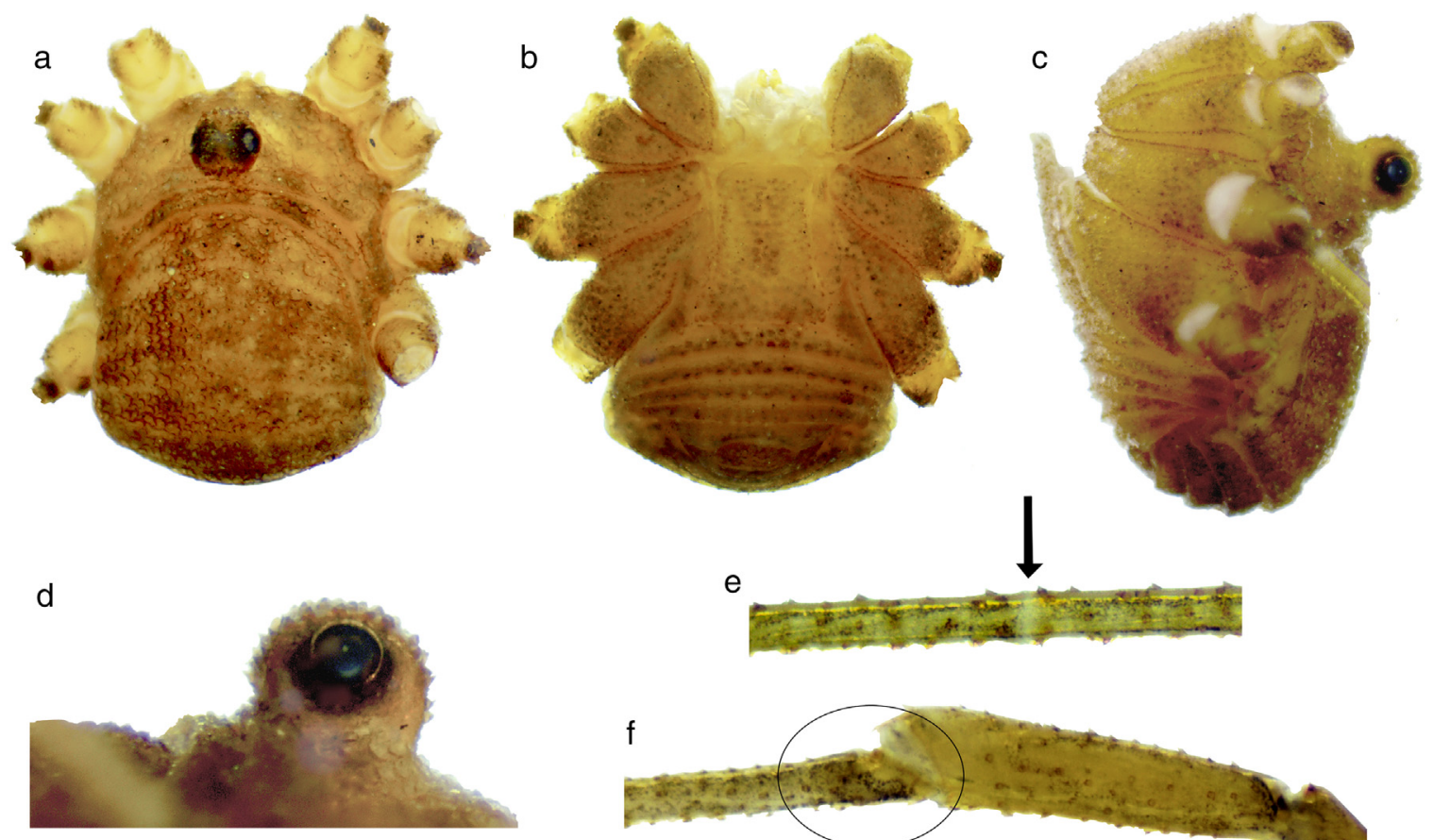

e
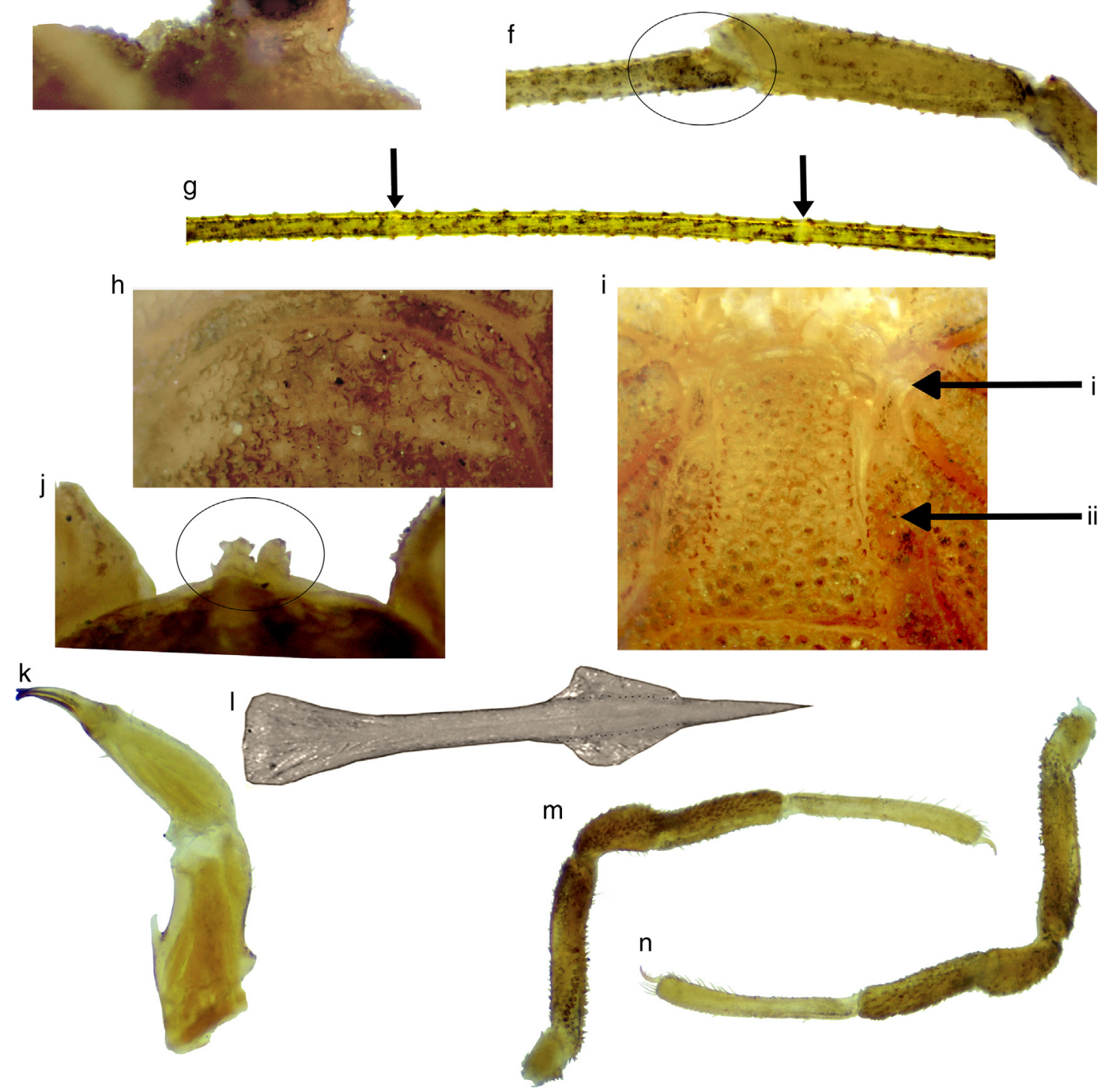

Figura 8. Krusa tuberculata. Macho: (a) vista dorsal, (b) ventral, (c) lateral, (d) oculario, (e) nódulo femoral de la pata II, la flecha indica dónde se encuentra, (f) tibia de la pata sin estigmas accesorios, (g) nódulos femorales en la pata II, las flechas muestran la ubicación, (h) depresiones del scutum, (i) opérculo genital y arculi genitales, la flecha superior muestra el arculi I y la inferior el II, (j) lamelas supraquelicerales, (k) quelícero en vista mesal, (l) pene en vista ventral, (m) pedipalpo, vista mesal y (n) ectal. 


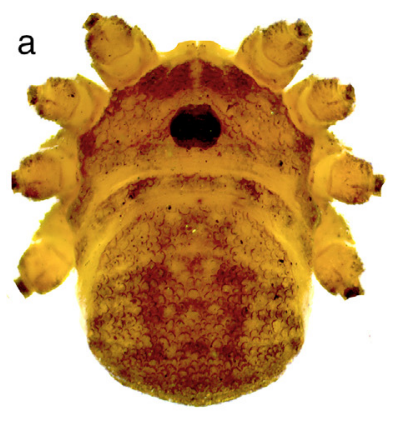

d

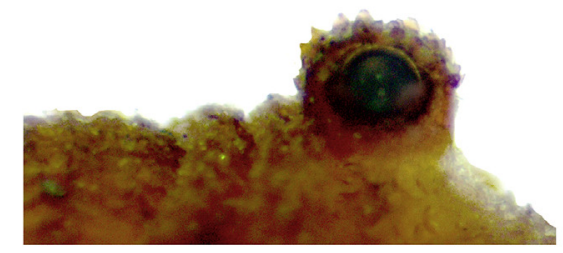

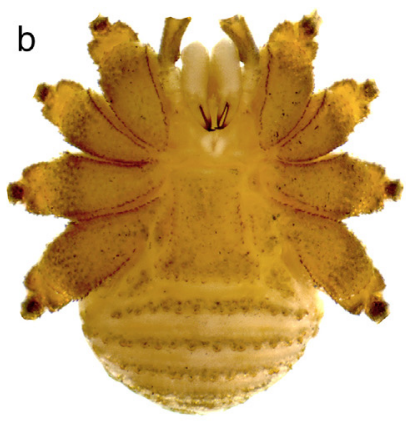

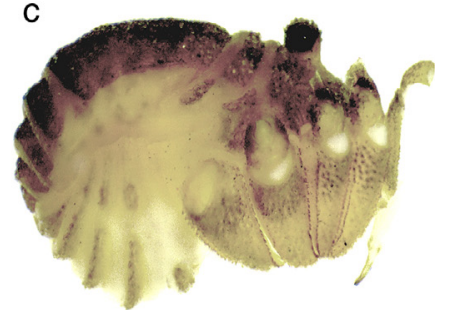

e

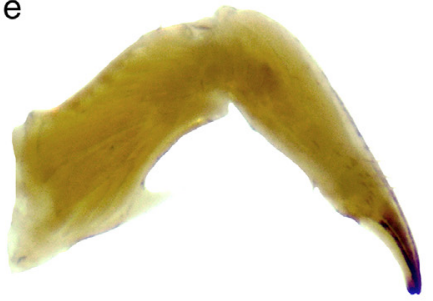

f

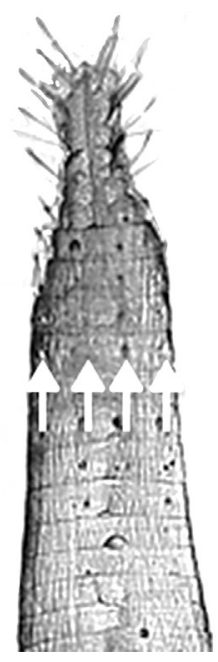

g

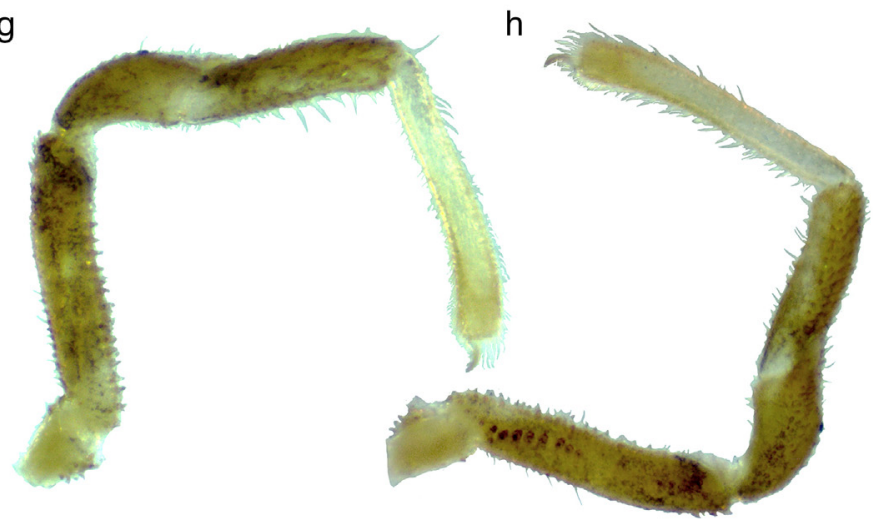

Figura 9. Krusa tuberculata. Hembra: (a) vista dorsal, (b) ventral, (c) lateral, (d) oculario, (e) quelícero vista mesal, (f) ovipositor con la ubicación de las setas, (g) pedipalpo, vista ectal y (h) mesal.

$8.83 \pm 0.63, \quad$ IV: $11.4 \pm 0.76$. Longitud del pedipalpo: $0.2 \pm 0.01 / 0.73 \pm 0.02 / 0.33 \pm 0.02 / 0.43 \pm 0.008 / 0.82 \pm 0.01$ Ovipositor $1.6 \pm 0.04$.

Historia natural: los ejemplares capturados fueron encontrados en bosque tropical caducifolio y bosque de niebla, sobre la vegetación.

Distribución: Veracruz (fig. 15).

\section{Resumen taxonómico}

Tipos: holotipo macho del estado de Veracruz, México; no date (H. S. Dybas). Chicago Natural History Museum: no examinado. Paratipos: un macho y una hembra, mismos datos que el holotipo. un macho: American Museum of Natural History: no examinado. Otros ejemplares: 9॰ y 7o (CNAN-Op001763). Afuera de la Cueva Ojo de Agua $\left(18.4^{\circ} 97^{\prime} 96^{\prime \prime} \mathrm{N}, 97.0^{\circ} 58^{\prime} 86^{\prime \prime} \mathrm{O}\right), 2,210 \mathrm{~m}$. Municipio de Tlilapan, Veracruz. 26/08/2014, cols. O. Francke, J. Cruz,
J. Arreguín y D. López. $2 \sigma^{7}$ y 8 ( (CNAN-Op001764). Inecol, Parada del autobús $\left(19.512222^{\circ} \mathrm{N}, 96.942778^{\circ} \mathrm{O}\right)$, 1,349 m. Municipio de Xalapa, Veracruz. 24/10/2013, cols. C. Zamora y J. Báez. $10^{7}$ y 1 juvenil (CNAN-Op000143). Tlacolulan $\left(19.642416^{\circ} \mathrm{N}, 96.9945^{\circ} \mathrm{O}\right), 1,889 \mathrm{~m}$. Municipio de Tlacolulan, Veracruz. 04/07/2007, cols. O. Francke, A. Valdez, H. Montaño. 120 y 7o (CAFBUM 492-509). Agüita fría $\left(19.522222^{\circ} \mathrm{N}, 96.98444^{\circ} \mathrm{O}\right), 1,434 \mathrm{~m}$. Municipio de Tlanelhuayucan, Veracruz. 02/12/2013, cols. C. Zamora, A. Balderas, L. Cervantes y J. Báez. 20 y 2o (CNAN-Op001483). La Isla $\left(20.344167^{\circ} \mathrm{N}, 97.249722^{\circ} \mathrm{O}\right), 43 \mathrm{~m}$. Municipio de Papantla, Veracruz. 1-31/07/2000. Sin colector. 10 (CNANOp001764). Camino al corazón $\left(18.89552^{\circ} \mathrm{N}, 97.01294^{\circ} \mathrm{O}\right)$, 893 m. Municipio de Fortín de Flores, Veracruz. Sin fecha, cols. J. Mendoza, S. Longhorn, E. Goyer y E. Hijmensen. $4 \sigma^{7}$ y 1 juvenil (CNAN-Op001765). Granja de Truchas «Los Manantiales» (18.79722 ${ }^{\circ} \mathrm{N}, 97.10519$ O), 1,142 m., municipio de Tlilapan, 

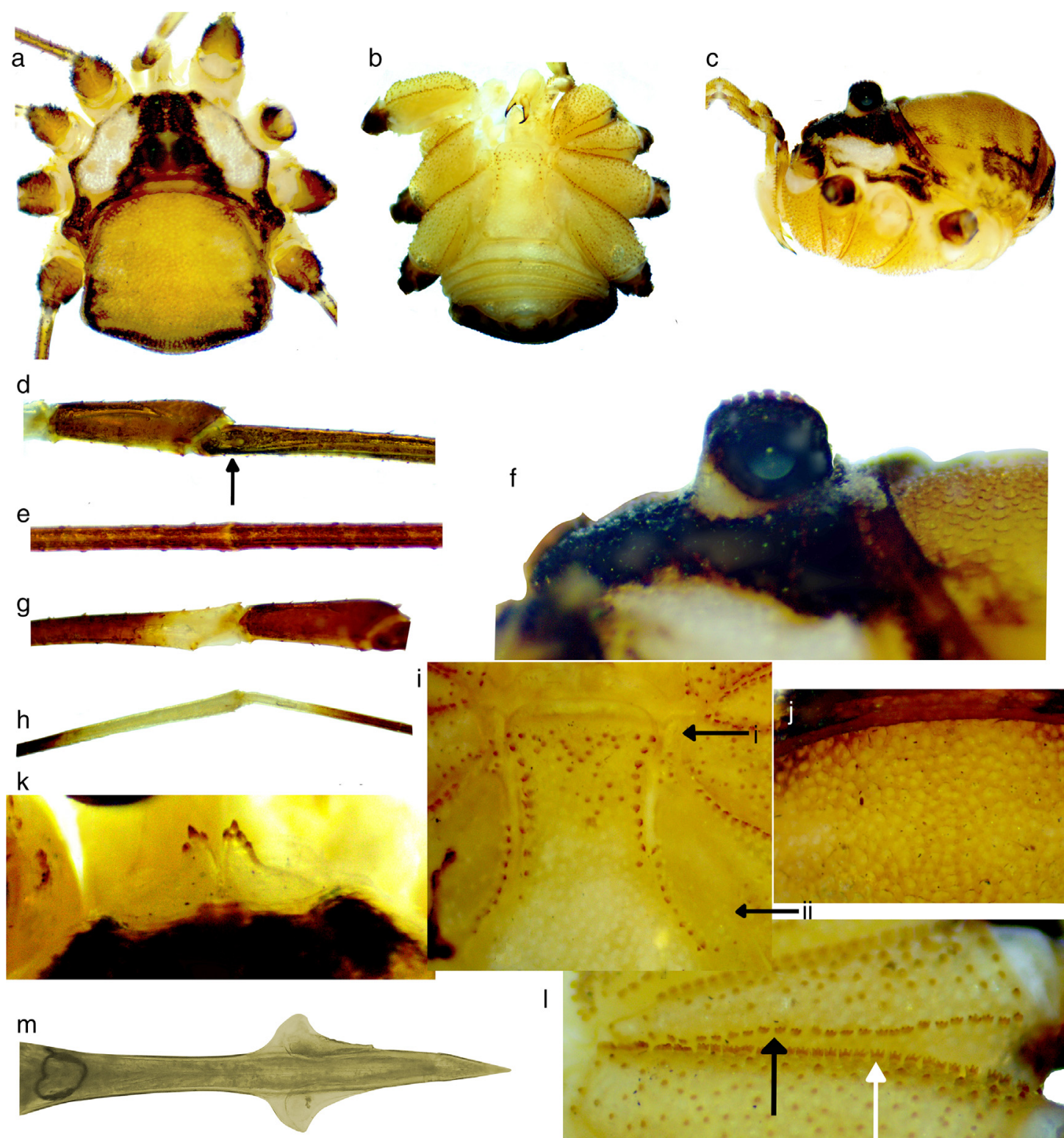

I
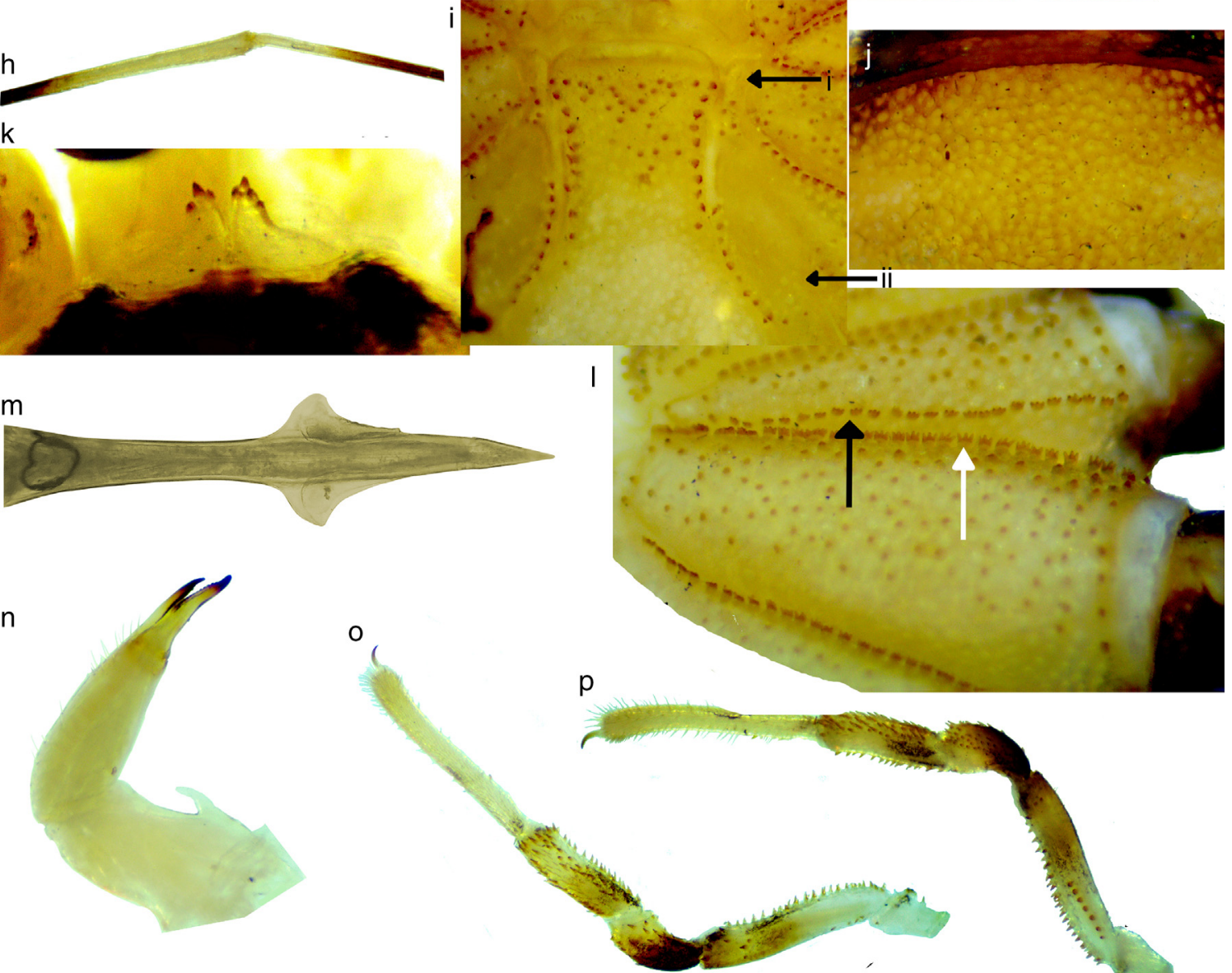

Figura 10. Krusa annulata. Macho: (a) vista dorsal, (b) ventral, (c) lateral, (d) estigma accesorio de la tibia, la flecha muestra su ubicación, (e) nódulo femoral de la pata II, (f) oculario, (g) y (h) coloración blanquecina de fémur y tibia de la pata II, (i) opérculo genital y arculi genitales, la flecha superior nos muestra el arculi I y la inferior el II, (j) depresiones del scutum, (k) lamelas supraquelicerales, (l) dentículos coxales, la flecha negra muestra el margen posterior y la blanca el anterior, (m) pene en vista ventral, (n) quelícero en vista mesal, (o) pedipalpo en vista mesal, (p) pedipalpo en vista ectal. 

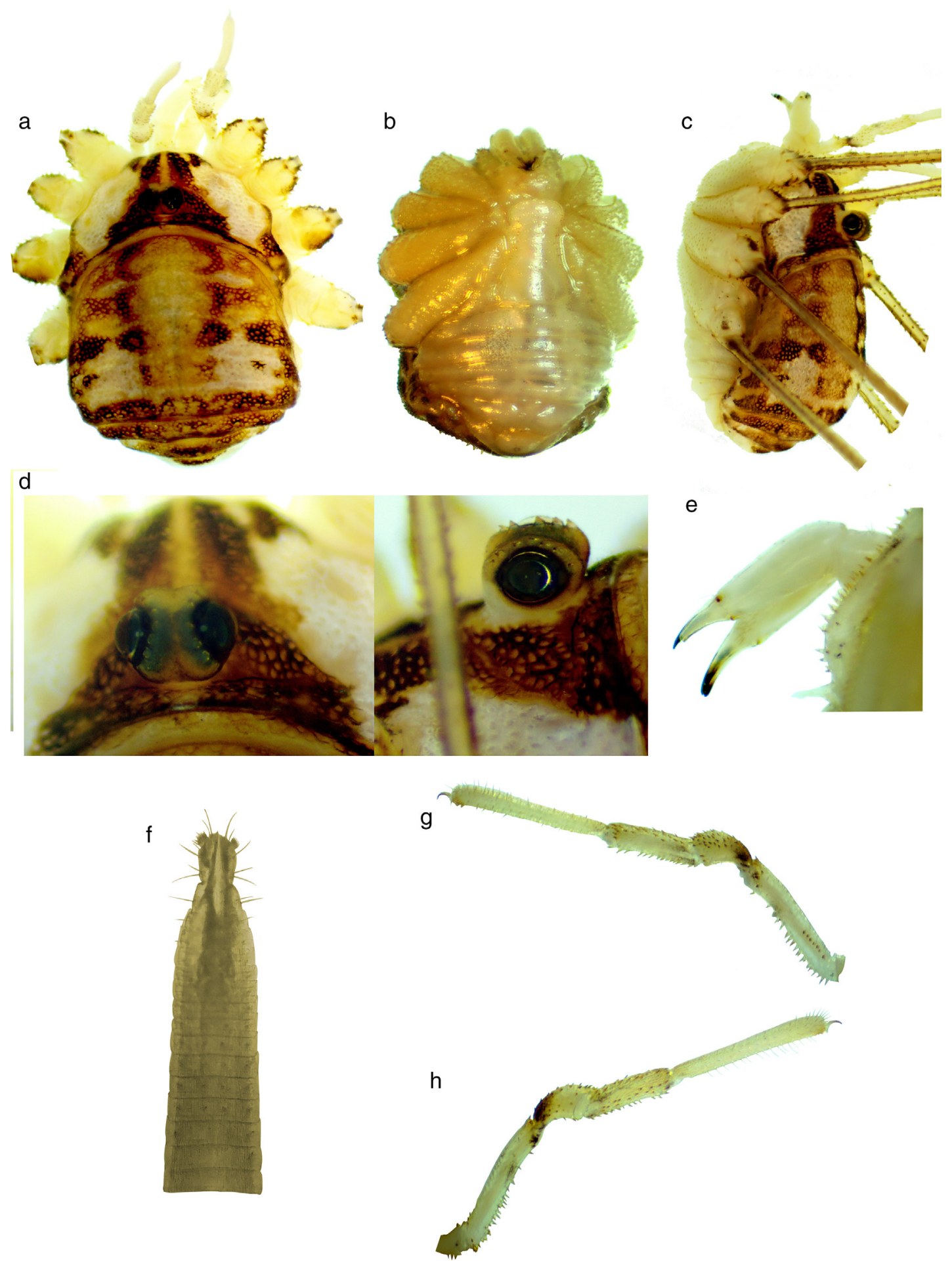

Figura 11. Krusa annulata. Hembra: (a) vista dorsal, (b) ventral, (c) lateral, (d) oculario en vista dorsal y lateral, (e) quelícero en vista mesal, (f) ovipositor, (g) pedipalpo, vista mesal y (h) ectal.

Veracruz. 21/01/2010, cols. O. Francke, C. Santibáñez, J. Cruz y A. Valdez. $30^{7}$ y 2 juveniles (CNAN-Op001766). Teocelo $\left(19.39979^{\circ} \mathrm{N}, 96.98174^{\circ} \mathrm{O}\right), 1,117 \mathrm{~m}$. Municipio de Teocelo, Veracruz. 18/12/2010, cols. J. Mendoza, S. Longhorn, E. Goyer y E. Hijmensen. 11 juveniles (CNAN-Op001767). Instituto Tecnológico Superior de Zongolica $\left(18.64994^{\circ} \mathrm{N}\right.$, $97.00508^{\circ}$ O), $1,298 \mathrm{~m}$. Municipio de Zongolica, Veracruz.
23/01/2010, cols. O. Francke, C. Santibáñez, J. Cruz y A. Valdez.

Krusa stellata Goodnight y Goodnight, 1946 (figs. 6-7, 14-15).

Krusa stellata Goodnight y Goodnight, 1946:12; Roewer, 1953:182; Kury y Cokendolpher, 2000:150; Hedin et al., 2012: 228. 

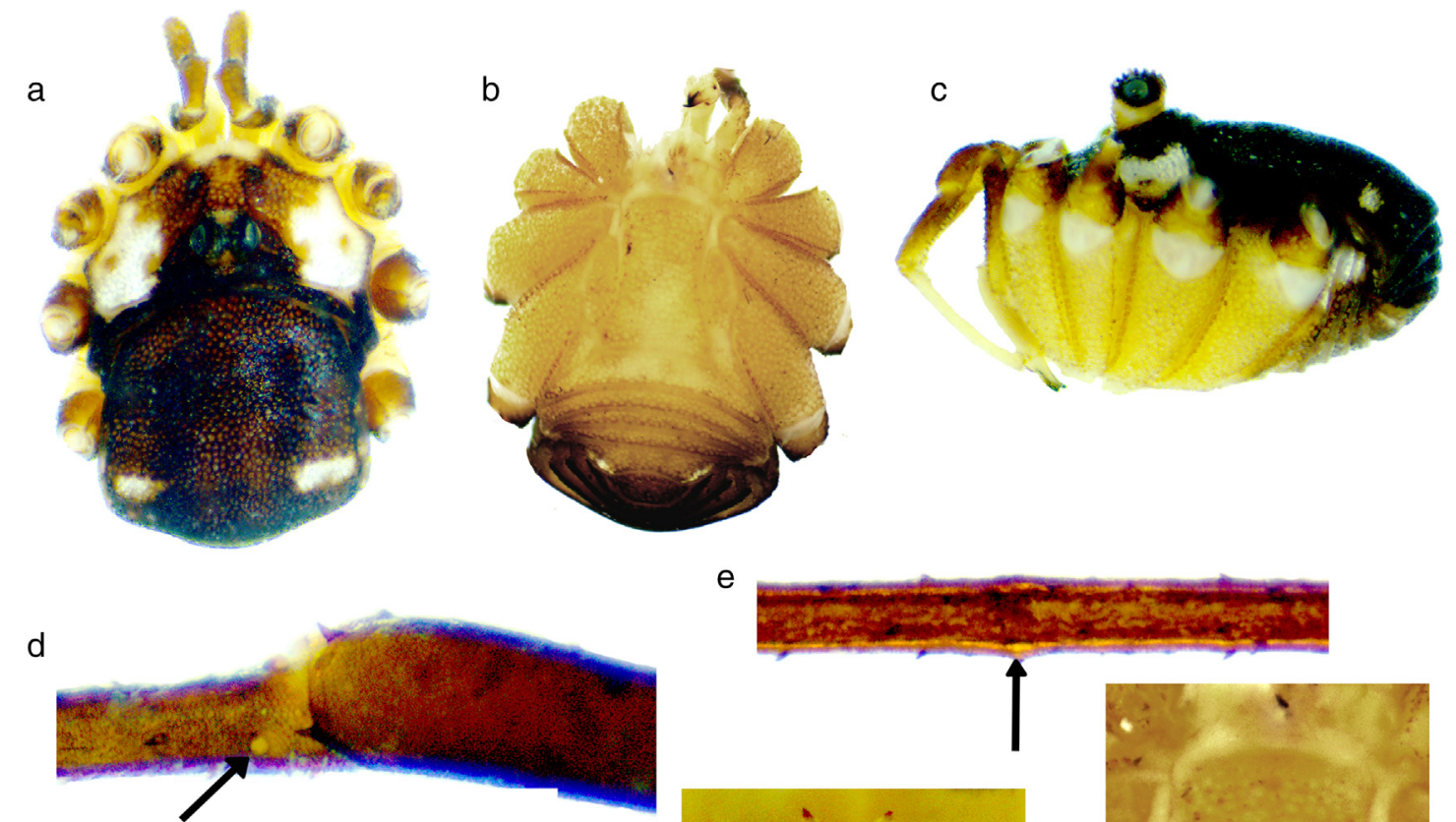

e
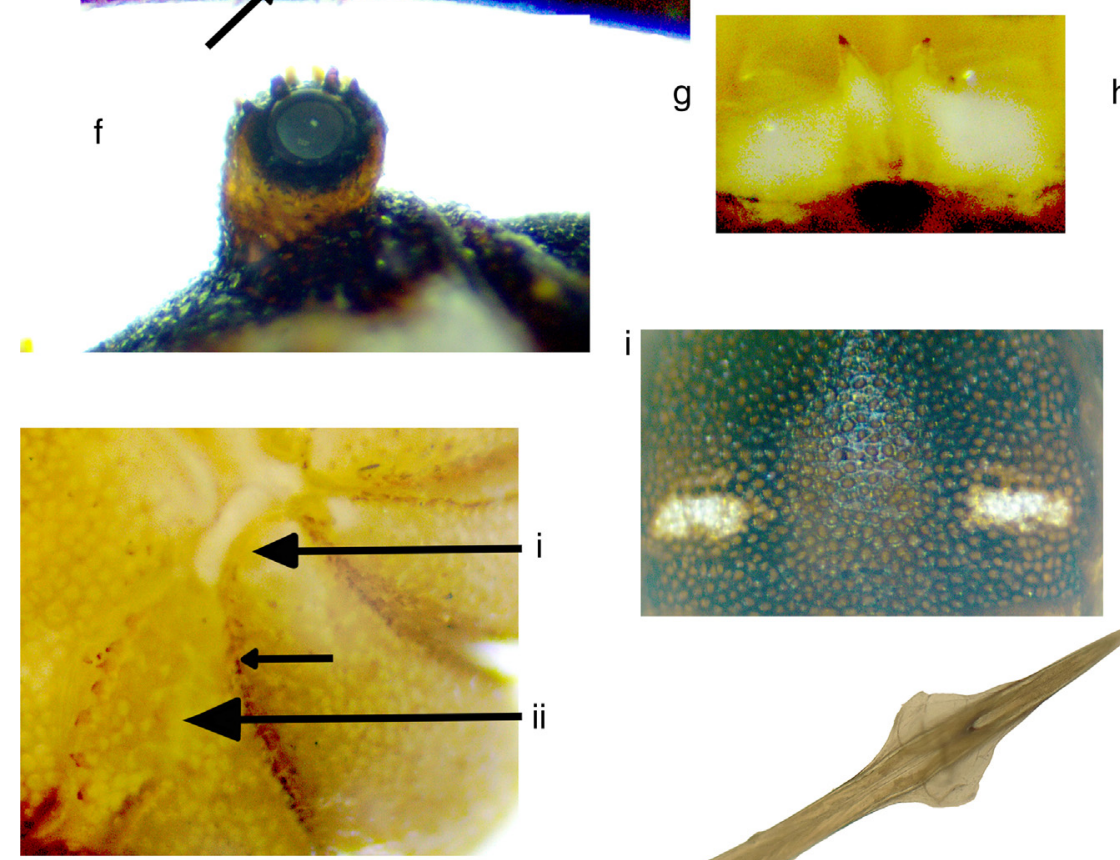

$\mathrm{h}$

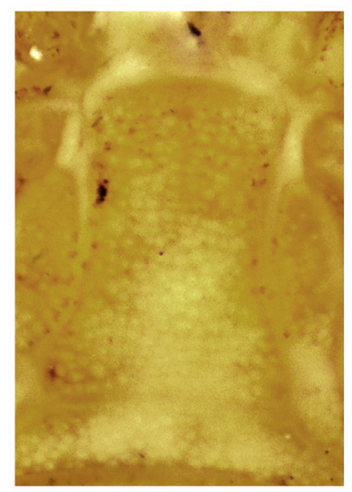

j
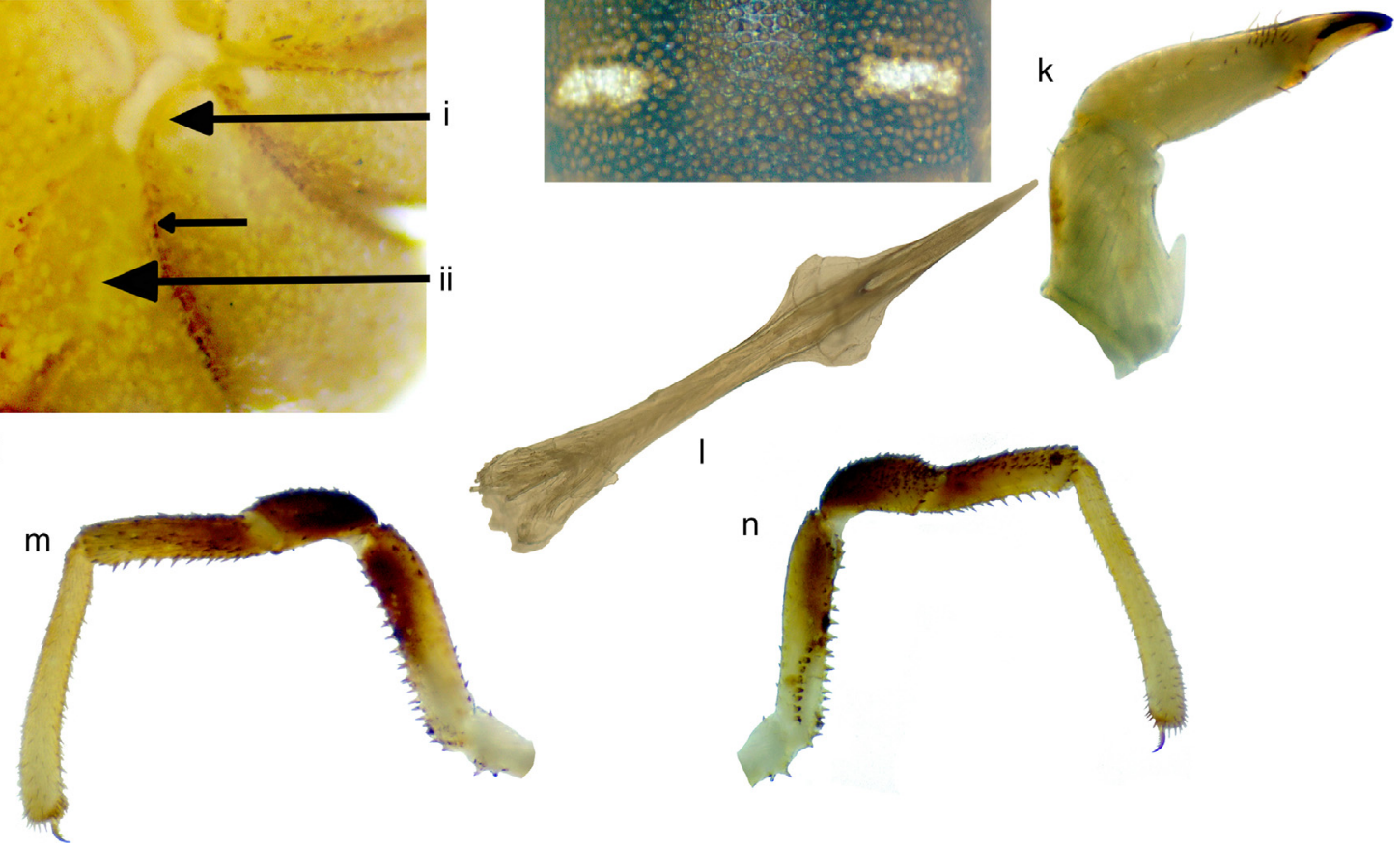

Figura 12. Krusa hidalguensis sp. nov. Macho: (a) vista dorsal, (b) ventral, (c) lateral, (d) estigma accesorio de la tibia: la flecha muestra su ubicación, (e) nódulo femoral de la pata II: la flecha nos indica dónde se encuentra, (f) oculario, (g) lamelas supraquelicerales, (h) opérculo genital, (i) depresiones del scutum, (j) arculi genitales, la flecha superior muestra el arculi I y la inferior el II, la flecha media muestra los dentículos tripunteados del margen anterior de las coxas, (k) quelícero, vista mesal, (l) pene, vista ventral, (m) pedipalpo en vista ectal y (n) mesal. 

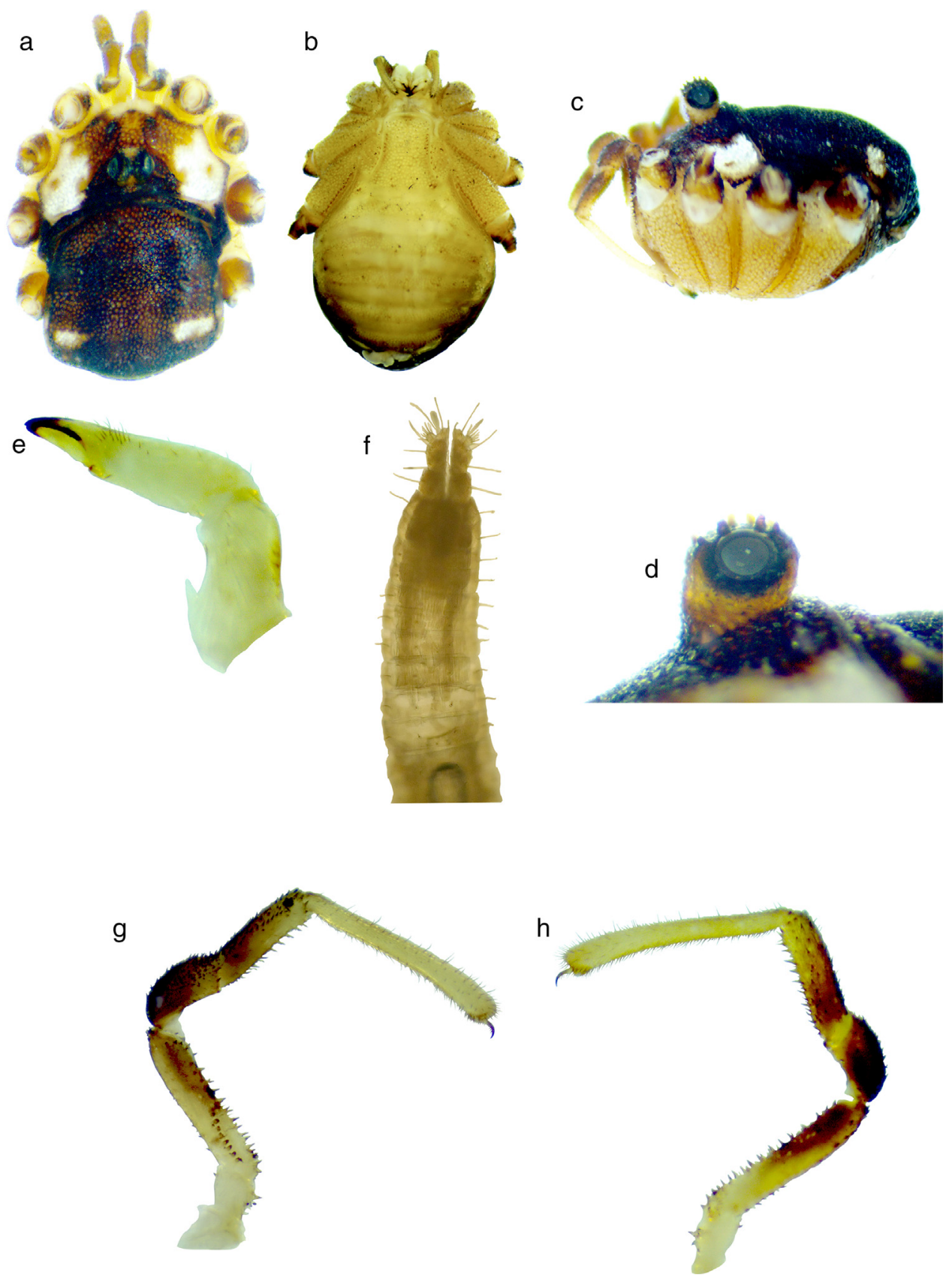

Figura 13. Krusa hidalguensis sp. nov. Hembra: (a) vista dorsal, (b) ventral, (c) lateral, (d) oculario, (e) quelícero, en vista mesal, (f) ovipositor, (g) pedipalpo en vista mesal y (h) ectal.

Diagnosis: toda la superficie dorsal cubierta de numerosos espinas pentapunteadas (figs. 6a, 7a), en la parte ventral estas se encuentran en los márgenes laterales (figs. 6b, 7b); lamelas supraquelicerales ornamentadas con los mismas espinas (fig. $7 \mathrm{~g}$ ); coxas con dentículos con 3 puntas que se extienden hasta la base cerca del trocánter, menos desarrollados en el margen anterior de la coxa III. La patela del pedipalpo presenta una apófisis muy reducida, aproximadamente $0.1 \mathrm{~mm}$.

Descripción del macho: longitud del cuerpo 3.74, cefalotórax 0.87 , scutum 1.63. Dorso: cefalotórax y segundo esternito prosomático, scutum, ELL T5 y ELL T6 con numerosas depresiones (figs. 6a, 6h), ornamentadas con espinas pentapunteadas (fig. 6h). El oculario es acanalado y estrecho en la base, ornamentado con las mismas espinas que se encuentran en el cefalotórax, con una fila de espinas pequeñas sobre cada carena (fig. 6f); el oculario se encuentra en el área posterior del cefalotórax (fig. 6a). Lamelas supraquelicerales expandidas en 2 placas redondeadas, ornamentadas con espinas pentapunteadas (fig. 6g). Vientre: ornamentado con depresiones y tubérculos ubicados en filas sobre cada esclerito, en los márgenes laterales con espinas pentapunteadas (fig. 6b); coxas ornamentadas con sedas y tubérculos, además presentan dentículos de 3 puntas en los márgenes anterior y posterior que se extienden hasta la base cerca del trocánter, menos desarrollados en el margen posterior de la coxa 

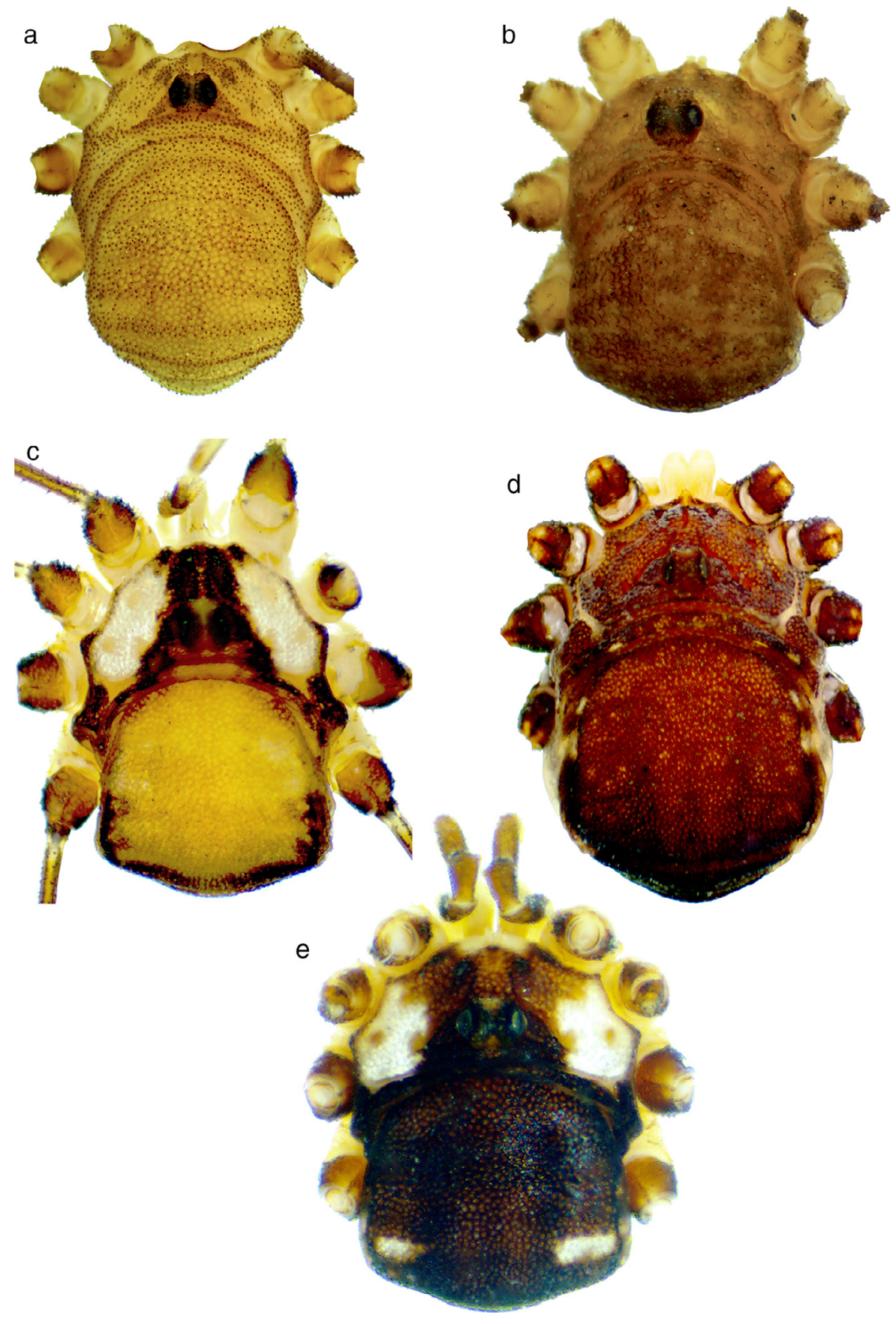

Figura 14. Patrones de coloración de la superficie dorsal. (a) Krusa stellata, (b) Krusa tuberculata, (c) Krusa annulata, (d) Krusa mexicana y (e) Krusa hidalguensis sp.nov.

III (fig. 6c). Opérculo genital con algunas sedas, tubérculos dispersos y en los márgenes laterales espinas pentapunteadas ubicadas en fila (fig. 6i). Arculi genitales: I y II ornamentados con tubérculos afilados, el II con una hilera de espinas pentapunteadas en el margen lateral cercano al opérculo genital (fig. 6i). Terguitos libres y opérculo anal con depresiones y espinas pentapunteadas. Quelíceros: longitud. 1.34. Primer segmento (basiquelicerito), con sedas en la parte media de la superficie mesal y con una proyección en la parte ventral. Segundo segmento con sedas gruesas en la parte apical llegando a los dedos (fig. 6j) y en la parte dorsal con sedas dispersas. Pedipalpos: medidas 0.18/0.87/0.26/0.57/1.10/2.98. Trocánter con dentículos y sedas en la parte dorsal y ventral; fémur en la parte ventral con dentículos puntiagudos dispersos, en la dorsal con sedas dispersas, en la parte mesal con una fila de dentículos en la base y en el margen apical (fig. 61), en la parte ectal con dentículos dispersos en la superficie apical (fig. 6m); patela con dentículos y sedas, las dentículos más numerosos en la parte dorsal, en la parte ventral con sedas, presenta una apófisis muy reducida; tibia con dentículos puntiagudos en la parte ventral, sedas dispersas y en la parte dorsal con numerosos dentículos; tarso cubierto de sedas; uña con 3 dentículos pequeños. Patas: medidas de los 


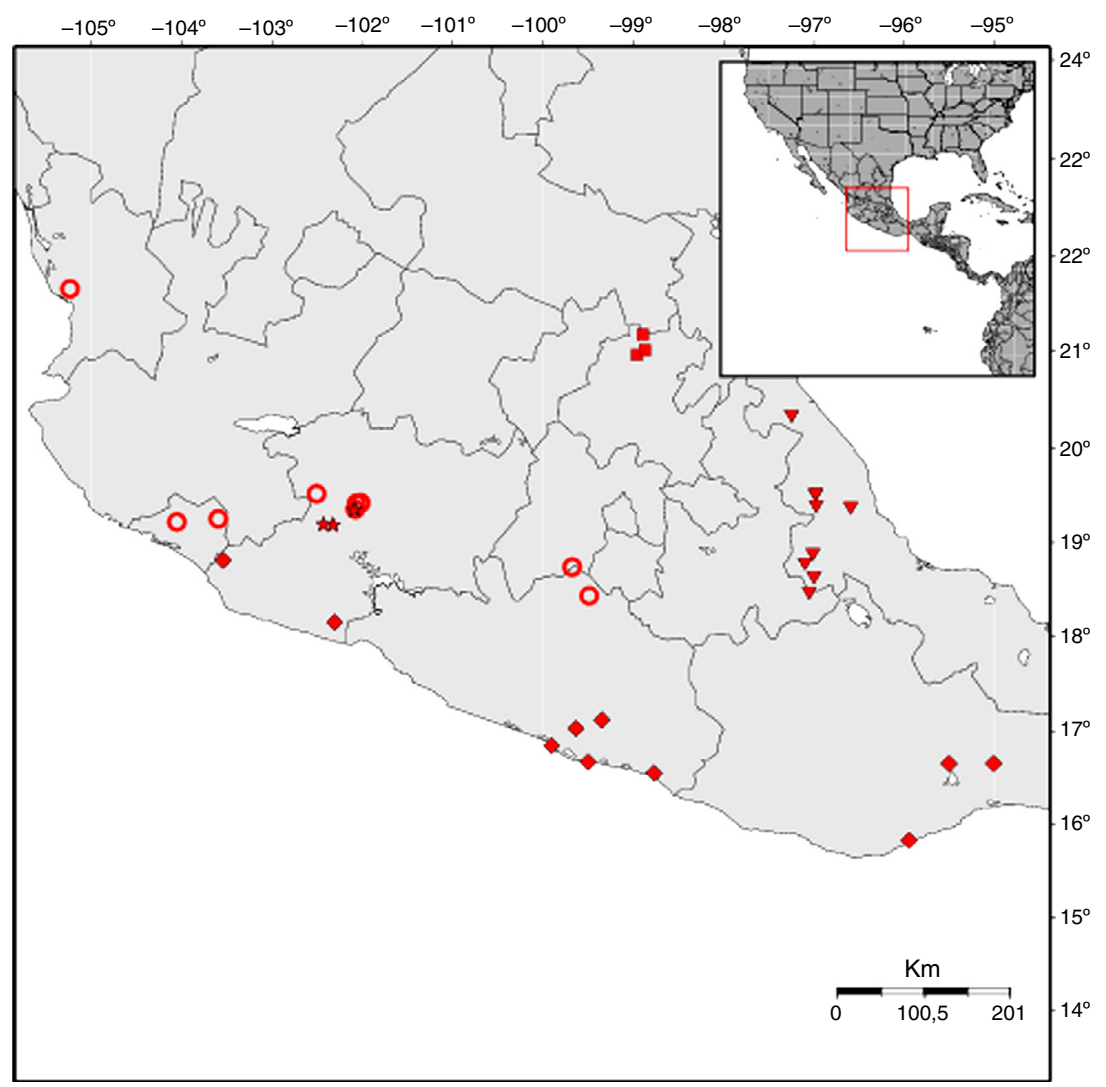

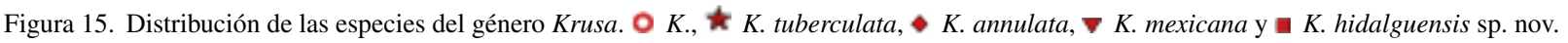

fémures: I: 6.79/II: 13.51/III: 7.05/IV: 10.03. Trocánter, fémur, tibia, patela y metatarso ornamentados con dentículos; trocánter sin ornamentación en las partes ventral y dorsal; en el fémur los dentículos son más conspicuos que en los otros segmentos; en el metatarso se encuentran en la parte basal y además presentan numerosas sedas al igual que en el tarso; con estigmas accesorios cerca de la base de la tibia (fig. 6d), el fémur II con un nódulo en la parte media (fig. 6e), tibia II y metatarsos con falsas articulaciones. Genitales masculinos: medida del pene: 1.78. Pene alado, estrecho de la parte media del tronco y más amplio basal y distalmente, la parte alada es pequeña y triangular, y el stylus es recto mientras que el ángulo lateral es de aproximadamente $85^{\circ}$. Las alas se encuentran a la mitad del pene (fig. 6k). Coloración: dorso de color pardo con manchas oscuras y claras dispersas, en el cefalotórax presenta una marca triangular oscura que engloba el oculario, el margen anterior también presenta esta coloración, mientras que los márgenes laterales son más claros (figs. 6a, 14a); las espinas que cubren la superficie son de color negro; vientre pardo oscuro, opérculo genital, coxas y quelíceros amarillentos; trocánter y tarso de los pedipalpos amarillentos y el resto de los segmentos color pardo oscuro, en el fémur la parte mesal presenta ambas coloraciones, en la parte basal amarillo y en la apical pardo oscuro; patas color pardo oscuro, el trocánter en los márgenes laterales pardo oscuro y las partes ventrales más claras.

Hembras (Parque Nacional de Uruapan, Michoacán) (fig. 7): en general presenta características similares a las del macho. Cuerpo grande y redondeado (fig. 7a-c); terguitos y esternitos amplios (fig. 7a, 7b); presenta numerosas espinas pentapunteadas en los márgenes del vientre. El ovipositor es delgado y está conformado por 19 segmentos, presenta 2 sedas en la parte media y 2 externas en cada segmento (fig. 7f). Dimorfismo sexual: el cuerpo de las hembras es redondeado y más grande que el de los machos $(4.922 \pm 0.53, \mathrm{n}=10$ vs. $3.59 \pm 0.22, \mathrm{n}=10)$; las patas son más cortas en las hembras; los machos presentan más dentículos en la parte ventral del fémur. Variación: los ejemplares machos adultos presentan la siguiente variación en cuanto a sus medidas morfológicas: longitud del cuerpo $3.59 \pm 0.22$; cefalotórax $0.83 \pm 0.09$; escudo abdominal $1.57 \pm 0.11$. Fémur I: $7.28 \pm 0.78$, II: $13.62 \pm 0.54$, III: $7.15 \pm 0.42$, IV: $10.07 \pm 0.26$. Longitud del pedipalpo: $0.16 \pm$ $0.005 / 0.87 \pm 0.03 / 0.24 \pm 0.01 / 0.57 \pm 0.036 / 1.19 \pm 0.005$. Pene $1.8 \pm 0.03$. Las hembras presentan las siguientes medidas: longitud del cuerpo 4.92 \pm 0.53 ; cefalotórax $0.94 \pm 0.08$; scutum $2.19 \pm 0.24$. Fémur I: $4.48 \pm 0.62$, II: $8.84 \pm 1.03$, III: $4.91 \pm 0.61$, IV: $7.16 \pm 0.85$. Longitud del pedipalpo: $0.15 \pm 0.02 / 0.86 \pm 0.04 / 0.25 \pm 0.02 / 0.53 \pm 0.04 / 1.12 \pm 0.05$. Ovipositor $2.13 \pm 0.01$. Presentan espinas pentapunteadas 0 dentículos puntiagudos en el margen lateral de los arculi genitales II, cerca al opérculo. El tamaño de los dentículos en la superficie ventral del fémur del pedipalpo varía. Uña del pedipalpo con 3 a 5 dentículos.

Historia natural: los ejemplares recientemente colectados fueron hallados en vegetación riparia y en casas que se encontraban cerca. Los organismos fueron colectados en hojarasca y troncos en descomposición donde había un alto grado de 
humedad, también se encontraron sobre las paredes de las casas (principalmente los estadios juveniles). Los ejemplares adultos se encontraron a las orillas de la Cascada la Tzararácua. Distribución: Colima, Guerrero, Michoacán y Nayarit (fig. 15).

\section{Resumen taxonómico}

Tipos: holotipo macho y paratipo hembra de Cascada Tzararácua, Michoacan (cerca de Uruapan), mayo 26, 1941 (C. Bolivar y B. F. Osorio Tafall); AMNH: no examinados. Otros ejemplares: 11 \% y $80^{7}$, Cascada la Tzararácua $\left(19.352388^{\circ} \mathrm{N}\right.$, $\left.102.078491^{\circ} \mathrm{O}\right), 1,500 \mathrm{~m}$. Municipio de Uruapan, Michoacán. Con las siguientes fechas de colecta 15/06/2013, 05/09/2013, cols. L. Álvarez, V. Guzmán, J. Ponce, J. Báez, M. Guzmán y L. Gaona. $2 \circ$ y $10^{\circ}$, Parque Nacional de Uruapan $\left(19.416667^{\circ} \mathrm{N}\right.$, $\left.102.066944^{\circ} \mathrm{O}\right), 1,640 \mathrm{~m}$. Municipio de Uruapan, Michoacán. Con las siguientes fechas 16/07/88, 30/07/88, col. Ma. García. 2 ㅇ y $30^{\circ}$, Chorros del Varal $\left(19.513889^{\circ} \mathrm{N}, 102.506944^{\circ} \mathrm{O}\right)$, 1,290 m. Municipio de Los Reyes de Salgado, Michoacán. Con las siguientes fechas 18/10/2003, 27/05/04 y 28/03/04. Col. M. Castillo. $1_{+}^{\circ}$, Presa Caltzontzin $\left(19.420556^{\circ} \mathrm{N}, 102.016944^{\circ} \mathrm{O}\right)$, 1,618 m. Municipio de Uruapan, Michoacán. 21/03/2010. Sin colector. 1o (CNAN-Op000958), río el Palillo $\left(21.6500^{\circ} \mathrm{N}\right.$, $\left.105.2333^{\circ} \mathrm{O}\right), 7 \mathrm{~m}$. Municipio de Tepic, Nayarit. 20/09/63. Sin colector. 1 \% y 1 juvenil, entronque a «El Sauz» carretera a Minatitlán $\left(19.25379^{\circ} \mathrm{N}, 103.59485^{\circ} \mathrm{O}\right) 1,006 \mathrm{~m}$. Municipio de Minatitlán, Colima. 29/08/2007, cols. O. Francke, H. Montaño, A. Ballesteros y A. Valdez. 2 juveniles (CNANOp001768), Balneario «El Salto» $\left(19.22087^{\circ} \mathrm{N}, 104.05128^{\circ} \mathrm{O}\right)$ 650 m. Municipio de Minatitlán, Colima. 26/05/2006, cols. O. Francke, H. Montaño, A. Ballesteros y A. Valdez. 1\%, afuera de la cueva de la Yerbabuena $\left(18.43830^{\circ} \mathrm{N}, 99.93011^{\circ} \mathrm{O}\right)$ $1,900 \mathrm{~m}$. Municipio de General Heliodoro Castillo, Guerrero. 13/07/2009, cols. O. Francke, A. Valdez, C. Santibáñez, A. Quijano y T. Palafox. 1९, Llano de transformador, Cacahuamilpa $\left(18.672222^{\circ} \mathrm{N}, 99.49^{\circ} \mathrm{O}\right), 1,160 \mathrm{~m}$. Municipio de Pilcaya, Guerrero. 29/06/2010. Col. A. Sánchez.

Krusa tuberculata Goodnight y Goodnight, 1946 (figs. 89, 14-15)

Krusa tuberculata Goodnight y Goodnight, 1946:12; Roewer, 1953:182; Kury y Cokendolpher, 2000: 150.

Diagnosis: dorso con depresiones profundas (fig. 8a, 8h), tubérculos grandes y conspicuos en cada esclerito (figs. 8, 9); oculario redondeado con una fila de espinas pequeñas sobre cada carena y en la parte media se encuentran dispersas (figs. 8d, 9d); en las coxas y opérculo genital se encuentran sobre toda la superficie (figs. 8b, 8c, 8i, 9b, 9c); opérculo genital con una fila de dentículos tripunteados en los márgenes laterales (fig. 8i), el arculi II también presenta este tipo de dentículos (fig. 8i).

Descripción del macho: longitud del cuerpo: 2.23, cefalotórax 0.73, scutum 1.06. Dorso: cubierto con depresiones irregulares profundas (fig. 8a). Cefalotórax, segundo terguito prosomático, scutum, ELL T5 y ELL T6 con depresiones. Oculario en la parte posterior del cefalotórax, restringido en la base, redondeado y ligeramente acanalado, con una fila de espinas sobre cada carena y en la parte media del oculario con ellas dispersas (fig. 8d). Lamelas supraquelicerales expandidas en 2 placas y con gránulos puntiagudos en la parte media y apical (fig. 8j). Escudo abdominal con numerosas depresiones; terguitos libres y opérculo anal cubierto por sedas y depresiones (figs. 8b, 8c). Vientre: coxas y opérculo genital con numerosos tubérculos grandes y afilados que cubren toda la superficie (fig. 8b, 8i). Márgenes anterior y posterior de las coxas con dentículos tripunteados, los cuales están reducidos en el margen anterior de la coxa III. Esternitos del IX al XV con filas de tubérculos grandes y conspicuos. Opérculo genital con dentículos de 3 puntas en los márgenes laterales (fig. 8i), arculi genitales I y II ornamentados con tubérculos, en el II con algunos dentículos tripunteados en el margen lateral cercano al opérculo genital (fig. 8i). Quelíceros: longitud 1.01. En el primer artejo presenta una proyección en la parte ventral y algunas sedas dispersas en la dorsal, en el segundo se encuentran sedas en la parte dorsal y en la mesal cerca de la base de los dedos (fig. 8k). Pedipalpos: Medidas: 0.15/0.59/0.29/0.38/0.69/2.1. Trocánter y fémur con dentículos pequeños en la parte ventral, el fémur además con algunos dentículos en la parte dorsal y en la superficie mesal con una hilera de 9 dentículos desde la base hasta la mitad, las partes laterales sin sedas, patela y tibia con numerosos dentículos negros pequeños (fig. 8m, 8n), ventralmente sin dentículos, tarso cubierto con sedas y presenta un mechón de sedas más oscuras cerca de la base de la uña del pedipalpo, apófisis patelar de $0.14 \mathrm{~mm}$, uña con 4 dentículos en la parte media. Patas: medidas de los fémures, I: 5.04/II: 8.73/III: 5.28/IV: 7.17. Trocánter, fémur, patela y tibia con numerosos dentículos, en el trocánter ausentes en la parte dorsal y ventral, en el fémur más numerosos y conspicuos, en la patela y tibia pequeños y se extienden de la parte basal a la media del metatarso, tarso cubierto de sedas; fémur de la pata II con un nódulo (fig. 8e), tibia II y metatarsos con falsas articulaciones. Genitales masculinos: medida del pene: 1.29. Pene alado, estrecho de la parte media del tronco y más amplio basal y distalmente, la parte alada es triangular alargada, y la base es redondeada, el stylus es recto y el ángulo lateral es de aproximadamente $85^{\circ}$. La parte alada se encuentra más hacia la parte apical (fig. 81). Coloración: cuerpo pardo con algunas manchas oscuras y claras, cefalotórax un poco más claro en la parte media, en el margen anterior y posterior más oscuros (fig. 14b), oculario pardo oscuro arriba y en la base claro. Vientre, opérculo genital y coxas pardos, en las coxas presenta un color más oscuro en la parte distal cerca de la articulación con el trocánter. Patas pardas, trocánter más oscuro en los márgenes laterales y en la articulación con el fémur presenta una coloración oscura. Pedipalpos amarillentos cubiertos con numerosos dentículos negros que dan apariencia de ser manchas oscuras, estas se encuentran en todos los segmentos a excepción del tarso, por lo cual presenta una coloración más clara. Quelíceros amarillentos.

Hembras: en general presentan características similares al macho. Grandes y redondeadas; las lamelas supraquelicerales están menos ornamentadas que en los machos; en los márgenes laterales del vientre se encuentran grupos de tubérculos separados de la hilera que se encuentra sobre cada esternito (fig. 9b, 9c). El ovipositor es delgado y presenta 19 segmentos, cada uno de estos con 2 sedas en la parte media 
y un par externo (fig. 9f). Dimorfismo sexual: las hembras son más grandes $(3.01 \pm 0.11$ vs. $2.27 \pm 0.08)$ y presentan los esternitos y terguitos más amplios. Los machos presentan mayor número de tubérculos en las lamelas. Las hembras presentan dentículos en la tibia del pedipalpo. Variación: los ejemplares revisados presentan las mismas características morfológicas y de coloración, en ocasiones algunos ejemplares pueden tener 2 nódulos femorales (fig. 8g). Las ornamentaciones en el oculario pueden ser muy conspicuas o reducidas. Los machos presentan las siguientes medidas: longitud del cuerpo $2.27 \pm 0.08$, cefalotórax $0.72 \pm 0.04$, scutum $1.08 \pm 0.04$. Fémur I: $4.88 \pm 0.33$, II: $8.01 \pm 0.51$, III: $5.05 \pm 0.37$, IV: $6.90 \pm 0.24$. Longitud del pedipalpo: $0.17 \pm 0.015 / 0.61 \pm 0.02 / 0.28 \pm 0.01 / 0.37 \pm 0.01 / 0.7 \pm 0.02$.

Pene $1.31 \pm 0.02$. Las hembras presentan las siguientes medidas: Longitud del cuerpo $3.013 \pm 0.11$, cefalotórax $0.82 \pm 0.05$, scutum $1.25 \pm 0.04$. Fémur I: $4.61 \pm 0.09$, II: $8.06 \pm 0.17$, III: $4.73 \pm 0.24$, IV: $6.61 \pm 0.28$. Longitud del pedipalpo: $0.17 \pm 0.02 / 0.58 \pm 0.03 / 0.28 \pm 0.01 / 0.38 \pm 0.01 /$ $0.70 \pm 0.02$. Ovipositor 1.60 .

Historia natural: recientemente se han colectado juveniles, los cuales fueron encontrados sobre las paredes de las canaletas de La Presa de Matanguarán en el municipio de Uruapan, en hojarasca con un alto grado de humedad.

Distribución: Michoacán (fig. 15).

\section{Resumen taxonómico}

Tipos: holotipo macho y paratipos macho y hembra de Cascada Tzaráracua, Michoacán (cerca de Uruapan), mayo 26, 1941 (C. Bolivar and B. F. Osorio Tafall): AMNH, no examinados. Otros ejemplares: $1 \sigma^{\top}, 10.1 \mathrm{~km}$ Carretera Uruapan-Nueva Italia, cerca de Matanguarán $\left(19.184726^{\circ} \mathrm{N}, 102.32628^{\circ} \mathrm{O}\right)$, $1,554 \mathrm{~m}$. Municipio de Uruapan, Michoacán. 03/07/2009. Sin colector. $80^{\circ}$, Zumpimito $\left(19.333333^{\circ} \mathrm{N}, 102.066667^{\circ} \mathrm{O}\right)$, 1,575 m. Municipio de Uruapan, Michoacán. 05/ 05/1988. Cols. B. Méndez y E.E.M. 3 o (CAFBUM 447-449), El Manguito $\left(19.19042^{\circ} \mathrm{N}, 102.42736^{\circ} \mathrm{O}\right), 1,324 \mathrm{~m}$. Municipio de Uruapan, Michoacán. Sin/fecha, col. A. Quijano. 25 juveniles (CAFBUM 451), presa de Matanguarán $\left(19.339444^{\circ} \mathrm{N}\right.$, $\left.102.096389^{\circ} \mathrm{O}\right), 1,533 \mathrm{~m}$. Municipio de Uruapan, Michoacán. 01/05/2014, cols. H. Gamiño, M. Gaona, V. Guzmán y L. Gaona.

\section{Krusa annulata Goodnight y Goodnight, 1945 (figs. 10, 11, 14, 15)}

Krusa annulata Goodnight y Goodnight, 1945:14; 1946:10; Roewer, 1953:182; Kury y Cokendolpher, 2000:150; Hedin et al., 2012: 228.

Diagnosis: tubérculos conspicuos y numerosos en las coxas y márgenes laterales y apical del opérculo genital en donde son más grandes (fig. 10i, 101). Las espinas presentes en el cuerpo son más conspicuas en comparación con otras especies. La parte apical del fémur (fig. 10g) y la tibia con una franja blanquecina (fig. 10h), estas también se encuentran presentes en la zona basal del tarso y los metatarsos. Presenta manchas plateadas en los márgenes laterales del cefalotórax y una marca triangular parda oscura que engloba el oculario (fig. 10a), oculario pardo y en la base más claro, scutum color pardo y en los márgenes laterales más oscuro (figs. 10a, 14c).
Descripción del macho: longitud del cuerpo: 3.18, ancho 2.98, cefalotórax 1.28, scutum 1.71. Dorso: rugoso; cefalotórax, segundo esternito prosomático, scutum, ELL T5 y ELL T6 cubiertos de numerosas pequeñas depresiones irregulares (fig. 10a, 10j); oculario ubicado en la parte posterior del cefalotórax, es alto, acanalado, restringido en la base y con una hilera de 7 espinas sobre cada carena (fig. 10f). Lamelas supraquelicerales bifurcadas y en los márgenes laterales presenta tubérculos conspicuos (fig. 10k). Scutum, terguitos libres y opérculo anal cubierto de depresiones y sedas. Vientre: las coxas con una hilera de dentículos tripunteados en los márgenes anterior y posterior (fig. 101), en la coxa III ausentes en el margen posterior, con tubérculos conspicuos y densos que se encuentran en toda la superficie. El opérculo genital presenta tubérculos puntiagudos en los márgenes laterales y desde el margen anterior hasta la mitad del opérculo (fig. 10i), en la parte basal solo se observan marcas irregulares que tienen apariencia de ser ligeras depresiones; arculi genitales I y II con sedas y depresiones, en el II presenta una fila de dentículos conspicuos en el margen lateral cerca del opérculo genital (fig. 10i). Esternitos del IX al XV cubiertos de ligeras depresiones (fig. 10b). Quelíceros: longitud 1.45. Presenta sedas grandes en toda la superficie dorsal, en el primer artejo con una proyección en la parte ventral y en el segundo presenta sedas en la superficie mesal cerca de la base de los dedos (fig. 10n). Pedipalpos: medidas. 0.29/0.78/0.42/0.61/0.97/3.07. Trocánter, fémur, patela y tibia con dentículos conspicuos; en el trocánter se encuentran en la superficie ventral; en el fémur se encuentran algunas en la parte apical en los márgenes laterales y en la parte basal de la superficie mesal con una hilera de 7 dentículos pequeños (fig. 10o, $10 p)$, mientras que en la parte ventral se encuentran dispersas en la base y en la parte media se dividen en 2 hileras que se ubican hacia los márgenes laterales; patela con numerosos dentículos en la superficie dorsal y casi ausentes en la ventral; en la tibia se encuentra una fila de dentículos conspicuos en la parte ventral, y en la dorsal numerosos dentículos (fig. $10^{\circ}, 10 \mathrm{p}$ ), los cuales se encuentran ausentes en la zona mesal. Tarsos cubiertos con sedas y en la superficie ventral cerca de la base se encuentran una o 2 espinas; con 4 dentículos pequeños en la uña. Apófisis patelar de $0.01 \mathrm{~mm}$. Patas: medidas de los fémures, I: 10.14 / II: 16.44 / III: 10.01 / IV: 11.92. Trocánter con dentículos conspicuos en los márgenes laterales; fémur con hileras longitudinales de dentículos siendo más grandes y conspicuos en la base y conforme se aleja hacia la parte apical más pequeños; patela con algunos dentículos pequeños dispersos; tibia con hileras de dentículos pequeños que terminan hasta la parte apical donde se encuentran en los márgenes del segmento; metatarso y tarsos cubiertos de numerosas sedas; tibias con estigmas accesorios (fig. 10d), fémur II con 1 nódulo (fig. 10e), metatarsos y tibia II con falsas articulaciones. Genitales masculinos: medida del pene: 2.03. Pene alado, estrecho de la parte media del tronco y más amplio de la parte basal y distal, la parte alada es triangular reducida, el ángulo lateral es de aproximadamente $85^{\circ}$ y el stylus es recto. La parte alada la presenta hacia la parte apical (fig. 10m). Coloración: parte lateral del cefalotórax con manchas plateadas, en estas se encuentran unas marcas irregulares amarillentas y los márgenes laterales pardos; en la parte media 
una marca triangular pardo oscuro que engloba el oculario y se extiende hasta el margen anterior; oculario pardo oscuro y en la parte basal más claro; segundo esternito prosomático, ELL T5 y ELL T6 pardo oscuro. Scutum pardo claro con algunas manchas oscuras a lo largo de los márgenes laterales y en el margen posterior con una línea oscura irregular (fig. 14c); terguito XII con manchas oscuras en la parte lateral mientras que los demás terguitos libres las presentan en la parte media. Opérculo anal pardo oscuro. Vientre y coxas amarillentas; con machas oscuras en los márgenes laterales derechos del arculi genital II. Patas pardas, trocánter pardo oscuro en los márgenes laterales, más claro dorsal y ventralmente; fémur y tibia pardos, en la parte apical presentan una franja blanquecina; tarso y metatarsos pardos y con franjas en la base (fig. 10g, 10h). Pedipalpos amarillentos, fémur con la parte distal obscura; patela y tibia con manchas oscuras sobre la superficie dorsal y tarsos claros. Quelíceros amarillentos.

Hembras: en general presenta características similares a los machos. Son grandes y redondeadas; con los terguitos más amplios (fig. 11a, 11b); lamelas supraquelicerales bifurcadas, sin ornamentación; coxas con menos tubérculos; pedipalpos delgados y con dentículos más pequeños; el ovipositor es delgado y está formado por 21 segmentos; presenta 2 sedas en la parte media y un par externo (fig. 11f). Dimorfismo sexual: las hembras son más grandes y redondeadas (miden $4.86 \pm 0.37$ vs. $3.36 \pm 0.25$ de los machos); las ornamentaciones del pedipalpo en los machos son más grandes y conspicuas. Variación: la apófisis patelar puede estar más desarrollada en algunos ejemplares. En los machos se pueden presentar ejemplares con dentículos muy conspicuos y numerosos y en algunos casos son un poco menos desarrollados; en el oculario se pueden encontrar desde 5 hasta 8 espinas sobre la carena. La mayor variación es en las ornamentaciones de los pedipalpos y patas. En los juveniles la forma del cuerpo es similar tanto en hembras como en machos. Los ejemplares machos presentan la siguiente variación en cuanto a sus medidas morfológicas: longitud del cuerpo $3.36 \pm 0.25$, ancho $2.83 \pm 0.10$, cefalotórax $1.27 \pm 0.03$, scutum $1.8 \pm 0.15$. Fémur I: $11.13 \pm 0.65$, II: $18.68 \pm 2.05$, III: $10.59 \pm 0.76$, IV: $12.94 \pm 1.39$. Longitud del pedipalpo: $0.24 \pm 0.03 / \quad 0.77 \pm 0.01 / 0.41 \pm 0.02 / 0.61 \pm 0.04 / 0.98 \pm 0.01$. Pene $2.07 \pm 0.12$. Las hembras presentan las siguientes medidas: longitud del cuerpo $4.86 \pm 0.37$, ancho $3.01 \pm 0.12$, cefalotó$\operatorname{rax} 1.32 \pm 0.09$, scutum $2.19 \pm 0.22$. Fémur I: $10.17 \pm 0.32$, II: $17.74 \pm 0.56$, III: $9.86 \pm 0.32$, IV: $12.6 \pm 0.50$. Longitud del pedipalpo: $0.28 \pm 0.004 / 0.78 \pm 0.05 / 0.42 \pm 0.02 / 0.6 \pm 0.02$ / $0.98 \pm 0.05$. Ovipositor $2.41 \pm 0.09$.

Historia natural: algunos de los ejemplares recientemente fueron colectados sobre un árbol de Brosimum alicastrum Swartz 1788 en Guerrero y en el ecotono de Selva Baja-Selva Mediana sobre paredes en Oaxaca. Distribución: Guerrero, Michoacán y Oaxaca (fig. 15).

\section{Resumen taxonómico}

Tipos: holotipo macho y paratipo hembra de Acapulco, Guerrero, agosto 20, 1943 (D. Peláez, M. Correa). AMNH: no examinado. 1\%, $1 \sigma^{7}$ Otros ejemplares: Las Peñitas $\left(16.555833^{\circ} \mathrm{N}, 98.772500^{\circ} \mathrm{O}\right), 9 \mathrm{~m}$. Municipio de la Unión de Isidoro Montes de Oca, Guerrero.16/01/2007. Cols. A. Pérez y A. L. Escalante. 10 (CNAN-Op000036), Acapulco $\left(16.851667^{\circ} \mathrm{N}, 99.909722^{\circ} \mathrm{O}\right), 43 \mathrm{~m}$. Municipio de Acapulco, Guerrero. 27/12/1944. Col. F. Bonet. 1o, Playa «El Petatillo» $\left(17.54130^{\circ} \mathrm{N}, 101.50050^{\circ} \mathrm{O}\right), 6 \mathrm{~m}$. Municipio de la Unión de Isidoro Montes de Oca, Guerrero 07/12/2008. Col. A. L. Escalante. 1o y 13 juveniles; La Majahua $\left(16.794444^{\circ} \mathrm{N}\right.$, $\left.99.838889^{\circ} \mathrm{O}\right), 8 \mathrm{~m}$. Municipio de Zihuatanejo de Azueta, Guerrero. 23/11/2014, cols. J. Ponce, A. Quijano y R. Teruel. $10^{x}$, misma localidad 19/03/2012, cols. J. Ponce. 6o y 4o; El terrero $\left(17.122778^{\circ} \mathrm{N}, 99.348333^{\circ} \mathrm{O}\right), 353 \mathrm{~m}$. Municipio de Juan R. Escudero, Guerrero. 07/08/2013. Col. L. López.1\%, Rancho «El Habillo» $\left(18.158056^{\circ} \mathrm{N}, 102.308333^{\circ} \mathrm{O}\right), 173 \mathrm{~m}$. Municipio de Lázaro Cárdenas, Michoacán. 08/12/2003. Sin colector. 1 juvenil (CAFBUM 481). Cañada Palos Marías $\left(18.8125^{\circ} \mathrm{N}, 103.533^{\circ} \mathrm{O}\right), 240 \mathrm{~m}$. Municipio de Coahuayana, Michoacán. 07/08/2003. Sin colector. 10 (CNAN-Op000971). $4 \mathrm{~km}$ al sureste del Pueblo Barra de la Cruz, Campamento Tortuguero $\left(15.4959^{\circ} \mathrm{N}, 95.5702^{\circ} \mathrm{O}\right), 5 \mathrm{~m}$. Municipio de Santiago Astata, Oaxaca. 18/09/2000. Col. C. Durán. 2o y 1 juvenil. Agua tibia en Nizanda $\left(16.658056^{\circ} \mathrm{N}, 95.011111^{\circ} \mathrm{O}\right)$, 79 m. Municipio de Asunción Ixtaltepec, Oaxaca. 09/12/2010, cols. J. Mendoza, S. Longhorn, E. Goyer y E. Hijmensen. 307, 2 甲 y 2 juveniles. Nizanda $\left(16.65817^{\circ} \mathrm{N}, 95.01057^{\circ} \mathrm{O}\right), 99 \mathrm{~m}$. Municipio de Asunción Ixtaltepec, Oaxaca.15/09/2009, cols. C. Santibáñez y A. Valdez.

\section{Krusa hidalguensis sp. nov. (figs. 12-15)}

Diagnosis: se diferencia de las otras especies por la presencia de espinas grandes y conspicuas sobre cada carena y en la parte media del oculario presenta granulaciones redondeadas (fig. 12f); los dentículos tripunteados en los márgenes anteriores de las coxas más desarrollados que los del margen posterior (fig. 12j); tibia del pedipalpo cubierto de dentículos pequeños y en la parte ventral con dentículos conspicuos (fig. 12n); quelíceros ornamentados en la superficie dorsal con algunos tubérculos y en el superficie mesal con tubérculos puntiagudos en el margen apical (fig. 12k); cuerpo pardo oscuro y en el cefalotórax presenta 2 manchas plateadas (figs. 12a, 14e).

Descripción del macho holotipo: longitud del cuerpo: 2.81, ancho 2.22, cefalotórax 1.01, scutum 1.46. Dorso: cefalotórax cubierto de depresiones poco profundas (fig. 12a, 12i); oculario acanalado, se encuentra en la parte posterior del cefalotórax, restringido en la base, con 5 o 6 espinas sobre cada carena y desde la parte media hasta la base presenta granulaciones (fig. 12f); lamelas supraquelicerales bifurcadas (fig. 12g); segundo terguito prosomático, ELL T5 y ELL T6, scutum, terguitos libres y opérculo anal ornamentados con depresiones sobre toda la superficie y las sedas están dispersas. Vientre: con depresiones sobre toda la superficie y sedas dispersas; coxas con numerosos tubérculos puntiagudos dispersos y en los márgenes de las coxas con dentículos tripunteados (fig. 12b), más desarrollados en los márgenes anteriores (fig. 12j) y ausentes en el margen posterior de la coxa III; opérculo genital con tubérculos ubicados más o menos en fila sobre los márgenes laterales y en el margen anterior dispersos (fig. $12 \mathrm{~h}$ ); arculi genitales I y II ornamentados con depresiones y sedas; en el II presenta dentículos puntiagudos en 
el margen lateral cercano al opérculo genital (fig. 12j). Quelíceros: longitud 1.31. Superficie dorsal con sedas dispersas y algunos gránulos redondeados; en el primer segmento en la parte ventral con una proyección y en la superficie mesal con algunos gránulos conspicuos en el margen apical (fig. 12k); en el segundo segmento presenta un grupo de sedas en la parte mesal cerca de los dedos. Pedipalpo: medidas: 0.27/0.77/0.32/0.44/0.94/2.74. Cubiertos de sedas; trocánter con dentículos en la superficie ventral, en el fémur presenta algunas dentículos pequeños en la base y en la zona distal de la parte dorsal, también presenta ventralmente dentículos grandes y conspicuos, los cuales en la base se encuentran dispersos y gradualmente se forman 2 líneas que se dirigen distalmente hacia los márgenes laterales, en la parte mesal con una hilera de 8 dentículos (fig. 12m, 12n); patela cubierta de dentículos pequeños, ausentes en la parte ventral; tibia cubierta de dentículos pequeños y en la superficie ventral más grandes y conspicuos igual que en el fémur; tarsos cubiertos de sedas, en la parte apical las presenta gruesas (fig. $12 \mathrm{~m}$, 12n); uña con 4 dentículos en la parte media. Patas: medidas de los fémures, I: 8.33/II: 14.86/III: 8.37/IV: 11.31. Trocánter con dentículos pequeños en los márgenes laterales; fémur con numerosos dentículos sobre toda la superficie; patela y tibia con dentículos más pequeños en comparación con las del trocánter y fémur, en la patela son pocas y se encuentran ubicadas en filas mientras que en la tibia son numerosos; metatarso y tarsos con sedas; presenta estigmas accesorios en la tibias (fig. 12d), nódulo femoral en la pata II (fig. 12e), metatarso y tibia II con falsas articulaciones. Genitales masculinos: medida del pene: 1.58. Pene alado, estrecho de la parte media del tronco y más amplio de la parte basal y distal, la parte alada es triangular y el stylus es recto. El ángulo lateral es de aproximadamente $85^{\circ}$ (fig. 121). Coloración: cuerpo pardo oscuro. En el cefalotórax presenta manchas plateadas y en la parte media desde el margen anterior hasta el posterior es pardo; oculario pardo oscuro en la superficie dorsal y más claro en el resto (figs. 12a, 14e); scutum pardo oscuro con una línea gruesa plateada a cada lado cerca del margen posterior; terguitos libres, opérculo anal, esternitos del IX al XIV y ELL E8 pardo oscuro, mientras que las piezas libres laterales de los externitos IX al XIV son blancas; la base del opérculo genital pardo y el resto más claro; arculi genital II pardo; coxas y arculi genital I amarillo; patas pardas; trocánter y base del fémur pardo oscuro; la parte distal de la tibia más clara y moteada con pardo oscuro; el metatarso en la zona distal blanquecino y el tarso en la basal. Trocánter y tarso del pedipalpo amarillos mientras que el fémur, patela y tibia son pardos. Quelíceros amarillentos.

Hembras (la Desviación a Nuevo Monterrey, municipio de Tlahuitepa, Hidalgo): oculario más bajo que en el macho; espinas del oculario pequeñas (fig. 13d); con pocos dentículos en la superficie ventral de la tibia del pedipalpo; los terguitos y esternitos más amplios; las demás características son similares a las de los machos. El ovipositor es delgado y está formado por 21 segmentos, presenta 2 sedas en la parte media y una cerca de los márgenes laterales en cada segmento (fig. 13f). Dimorfismo sexual: las hembras presentan el cuerpo redondeado y más grande $(3.9 \pm 0.16$ vs. $2.81 \pm 0.22)$, los terguitos y esternitos son más amplios. Las hembras no presentan tubérculos puntiagudos en los quelíceros. Variación: las espinas alrededor de cada carena pueden ser conspicuas o más bajas en algunos ejemplares; la apófisis patelar del pedipalpo varía desde 0.2 a $0.5 \mathrm{~mm}$ y la tibia presenta menos dentículos que las que presenta el holotipo; la coloración puede variar ya que en ocasiones se encuentran ejemplares con manchas blanquecinas en el margen posterior del segundo terguito prosomático y en el primer segmento del scutum. Los ejemplares machos presentan la siguiente variación en cuanto a sus medidas morfológicas: longitud del cuerpo $2.81 \pm 0.22$, ancho $2.35 \pm 0.11$, cefalotórax $0.99 \pm 0.02$, scutum $1.41 \pm 0.07$. Fémur I: $9.03 \pm 0.85$, II: $16.06 \pm 1.70$, III: $9.04 \pm 0.83$, IV: $12.12 \pm 1.14$. Longitud del pedipalpo: $0.26 \pm 0.01 / 0.76 \pm 0.02 / 0.32 \pm 0.01 / 0.44 \pm 0.02 / 0.93 \pm 0.01$.

Pene $1.586 \pm 0.02$. Las hembras presentan las siguientes medidas: longitud del cuerpo $3.9 \pm 0.16$, ancho $2.67 \pm 0.13$, cefalotórax $1.19 \pm 0.06$, scutum $1.44 \pm 0.05$. Fémur I: $8.57 \pm 0.66$, II: $14.76 \pm 0.94$, III: $8.54 \pm 0.69$, IV: $11.15 \pm 0.89$. Longitud del pedipalpo: $0.23 \pm 0.01 / 0.72 \pm 0.01 / 0.30 \pm 0.01$ / $0.42 \pm 0.02 / 0.93 \pm 0.01$. Ovipositor $1.76 \pm 0.02$.

Historia natural: los ejemplares colectados recientemente se encontraron sobre la vegetación en Bosque tropical caducifolio perturbado.

Distribución: Hidalgo (fig. 15).

\section{Resumen taxonómico}

Holotipo o (CNAN-T0945): La Desviación a San Cristóbal $\left(20.96537^{\circ} \mathrm{N}, 98.96537^{\circ} \mathrm{O}\right), 1,469 \mathrm{~m}$. Municipio de Tlalchinol, Hidalgo. 10/09/2014, cols. O. Francke, J. Cruz, D. Barrales, A. Guzmán y J. Arreguín. 207 paratipos (CNAN-T0946), La Curva del Santo Niño $\left(21.17579^{\circ} \mathrm{N}, 98.89982^{\circ} \mathrm{O}\right), 2,077 \mathrm{~m}$. Municipio de Chapulhuacán, Hidalgo. 24/10/2013, cols. O. Francke, C. Santibáñez, J. Cruz y A. Guzmán. 9 p paratipos (CNAN-T0947), La Desviación a Nuevo Monterrey $\left(21.01410^{\circ} \mathrm{N}, 98.87756^{\circ} \mathrm{O}\right)$, 1,498 m. Municipio de Tlahuitepa, Hidalgo. 10/09/2014, cols. O. Francke, J. Cruz, D. Barrales, A. Guzmán y J. Arreguín.

Etimología: el epíteto específico deriva del nombre del estado donde se colectaron los ejemplares tipo.

\section{Comentarios taxonómicos}

Goodnight y Goodnight describen el género Krusa en 1947, seleccionando como especie tipo a $K$. mexicana y postularon como caracteres diagnósticos: 1) el dorso sin espinas, 2) la presencia de espinas pequeñas alrededor de cada carena del oculario, 3) un nódulo en el fémur II, y por último 4) la presencia de dentículos tripunteados en los márgenes de las coxas. Al publicar las descripciones de las demás especies del género antes de 1947, consideramos que los usos previos del nombre genérico se constituyen en nomina nuda. El nombre genérico se mantiene como Krusa entendiendo que aunque el uso en las especies descritas antes de 1947 constituyen nomina nuda, esto no significa que el nombre genérico no sea disponible o válido. Las especies son válidas aun cuando se hayan propuesto en combinación con un nombre genérico no válido o disponible, y por ende las combinaciones se vuelven válidas a partir de 1947.

Las características diagnósticas del género no son homogéneas en las especies descritas antes de 1947 y estas se ubican 

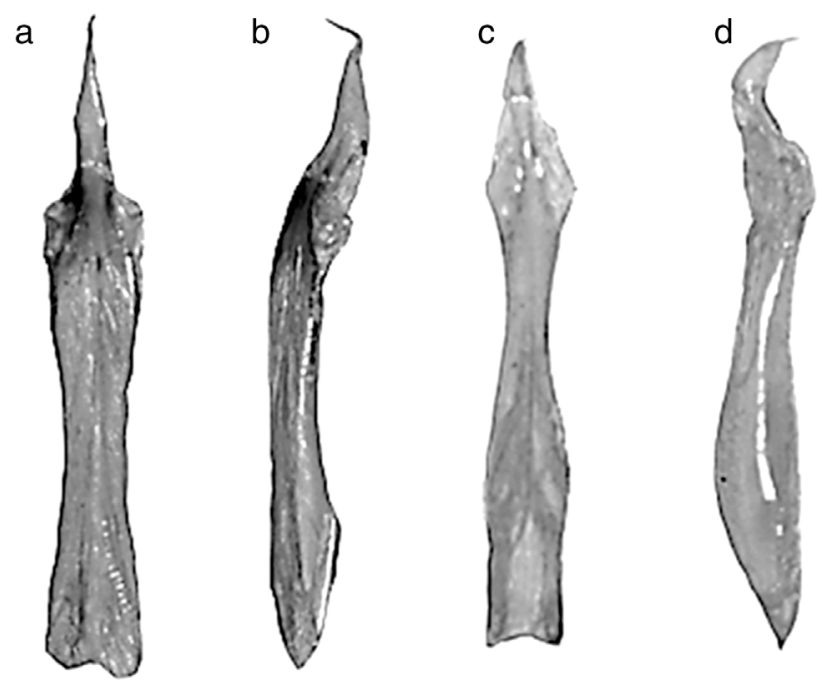

Figura 16. Genitales de «K.» metallica (a y b), «K.»flava (c y d).

en el género basándose únicamente en la presencia de nódulos; por lo que al revisar las especies mexicanas se encuentra que K. stellata presenta espinas dispersas sobre el dorso y también se pueden encontrar en los márgenes del vientre, difiriendo de la primera característica diagnóstica para el género. K. flava y $K$. metallica no presentan espinas en el oculario y con respecto al último carácter que es la presencia de dentículos tripunteados, se observó que este tipo de ornamentación también se encuentran presente en los géneros Geaya Roewer, 1910, Prionostemma Pocock, 1903 y Trachyrhinus Weed, 1892.

Por lo anterior, en este trabajo se rediagnostica el género Krusa con base en las características de la especie tipo, proponiéndose los siguientes caracteres como diagnósticos: 1) oculario con una fila de espinas pequeñas alrededor de cada carena, en algunos casos se pueden encontrar algunas espinas dispersas en la parte media, 2) dorso rugoso con numerosas depresiones de diferentes tamaños, en ocasiones también en la parte ventral, 3) coxas y opérculo genital ornamentadas con numerosos gránulos puntiagudos dispersos, 4) pene alado, la parte alada es triangular, stylus recto, 5) ovipositor en el que cada segmento tiene 2 sedas en la parte media y una cerca de los márgenes laterales.

Aplicando el conjunto de caracteres anteriores a las especies que hasta ahora constituyen el género, se propone que el género Krusa quede integrado por las especies $K$. stellata, $K$. annulata, K. mexicana, K. tuberculata y $K$. hidalguensis sp. nov., las cuales comparten los caracteres mencionados anteriormente. Se reconoce a otro grupo de especies constituido por las especies nominativas «K.» flava $y$ «K.» metallica. Así, las especies de Krusa (sensu stricto) presentan el oculario ornamentado con espinas alrededor de cada carena y el pene con alas en forma triangular; mientras que «K.» metallica $y$ «K.»flava, presentan el oculario liso y el pene lobulado (fig. 16) como principales diferencias morfológicas. Este arreglo de especies coincide con la ubicación de las especies de Krusa en 2 grupos, como lo obtuvieron Hedin et al. (2012) con datos moleculares.

La presencia de nódulos, como anteriormente fue mencionado por Tourinho (2004), no debe ser considerada como una característica definitiva para la delimitación de géneros en la subfamilia Gagrellinae y coincidimos en que para el trabajo sistemático en el grupo se deben de tomar en cuenta y con mayor peso otras características morfológicas y genitales.

Finalmente, como una consecuencia de muestro trabajo, proponemos el acto nomenclatural consistente en la resurrección del género Krusella Roewer (1953) que tiene como especie tipo a Krusella pilipes de Venezuela, la cual, solo con base en la presencia de nódulos, Ringuelet (1954) propuso ubicar bajo sinonimia con Krusa.

\section{Agradecimientos}

Al Consejo Nacional de Ciencia y Tecnología por la beca para estudios de grado de la primera autora en el Programa Institucional de Maestría en Ciencias Biológicas de la Universidad Michoacana de San Nicolás de Hidalgo. A todos los que contribuyeron en la colecta de los ejemplares: A. Balderas, A. Ballesteros, A. Escalante, A. Guzmán, A. Pérez, A. Quijano, A. Valdez, B. Méndez, C. Durán, C. Santibáñez, C. Zamora, D. Barrales, D. López, E. Castillo, E. Goyer, E. Hijmensen, F. Bonet, H. Gamiño, H. Montaño, J. Arreguín, J. Báez, J. Cruz, J. Mendoza, L. Álvarez, L. Cervantes, L. López, M. Gaona, Ma. García, M. Guzmán, S. Longhorn y V. Guzmán. Los ejemplares fueron colectados al amparo del Permiso de Colecta Científica FAUT-0175 otorgado a O. Francke por la Semarnat. A Juan Maldonado Carrizales, Ana F. Quijano Ravell y Diana Alejandra Gutiérrez Cortés por su apoyo en la elaboración de las figuras.

\section{Referencias}

Cokendolpher, J. C. (1981). Revision of the genus Trachyrhinus Weed (Opiliones, Phalangioidea). Journal of Arachnology, 9, 1-18.

Cruz-López, J. A. (2013). Guerrobunus franckei, una nueva especie de opilión troglobio de México (Opiliones: Laniatores: Phalangodidae). Revista Mexicana de Biodiversidad, 84, 1137-1141.

Cruz-López, J. A. y Francke, O. F. (2012). Una nueva especie del género Paramitraceras Pickard-Cambridge (Opiliones: Laniatores: Stygnopsidae) de Veracruz, México. Revista Ibérica de Aracnología, 20, 17-23.

Cruz-López, J. A. y Francke, O. F. (2013a). Two new species of the genus Paramitraceras Pickard-Cambridge (Opiliones: Laniatores: Stygnopsidae) from Chiapas, México. Zootaxa, 3641, 481-490.

Cruz-López, J. A. y Francke, O. F. (2013b). On the enigmatic genus Philora: familial assignment and taxonomic revision (Opiliones: Laniatores: Stygnopsidae). Journal of Arachnology, 41, 291-305.

Cruz-López, J. A. y Francke, O. F. (2015). Cladistic analysis and taxonomic revision of the genus Karos Goodnight \& Goodnight, 1944 (Opiliones, Laniatores, Stygnopsidae). The Linnean Society of London, Zoological Journal of the Linnean Society, 175, 827-891.

Cruz-López, J. A. y Ubick, D. (2015). A new epigean harvestman of the genus Guerrobunus (Laniatores: Phalangodidae), from Hidalgo, Mexico, with taxonomic notes about the genus. Zootaxa, 3980, 189-200.

Giribet, G. (2011). Shearogovea a new genus of Cyphophthalmi (Arachnida, Opiliones) of uncertain position from Oaxacan Caves, Mexico. Breviora, $528,1-7$.

Goodnight, C. J. y Goodnight, M. L. (1945). Additional Phalangida from Mexico. American Museum Novitates, 1281, 1-17.

Goodnight, C. J. y Goodnight, M. L. (1946). Additional studies of the phalangid fauna of Mexico. American Museum Novitates, 1310, 1-17.

Goodnight, C. J. y Goodnight, M. L. (1947). Phalangida from Tropical America. Fieldiana: Zoology, 32, 1-59. 
Groh, S. y Giribet, G. (2015). Polyphyly of Caddoidea, reinstatement of the family Acropsopilionidae in Dyspnoi, and a revised classification system of Palpatores (Arachnida: Opiliones). Cladistics, 31, 277-290.

Hadley, A. (2010). CombineZP. Image stacking software. http://combinezp.software.informer.com/. Descargado 15 Sep 2014.

Hedin, M., Tsurusaky, N., Macías-Ordoñez, R. y Shultz, J. O. (2012). Molecular systematics of sclerosomatid harvestmen (Opiliones, Phalangioidea, Sclerosomatidae): geography is better than taxonomy in predicting phylogeny. Molecular Phylogenetics and Evolution, 62, 224-236.

Kury, A. B. y Cokendolpher, J. C. (2000). Opiliones. En J. Llorente-Bousquets, E. González-Soriano, y N. Papavero (Eds.), Biodiversidad, taxonomía y biogeografía de artrópodos de México: hacia una síntesis de su conocimiento. Vol. II. (pp. 137-157). México, D.F.: Conabio/UNAM.

Mello-Leitão, C. F. (1933). Quatro novos Palpatores neotropicos. Annaes da Academia Brasileira de Sciencias, Rio de Janeiro, 5, 99-103.

Pérez-González, A. (2006). Revisão sistemática e análise filogenética de Stygnommatidae (Arachnida: Opiliones: Laniatores). Tesis doctoral. Programa de Pós-graduação em Ciências Biológicas (Zoologia). Museu Nacional, Universidad Federal de Rio de Janeiro.

Pickard-Cambridge, F. O. (1905). Araneidea and Opiliones. En F. D. Godman y O. Salvin (Eds.), Biologia Centrali- Americana, Vol. II (pp. 546-585). London: R.H. Porter Ed.

Pocock, R. I. (1903). Fifteen new species and two new genera of tropical southern Opiliones. Annals and Magazine of Natural History, 11, 433-450.

Ringuelet, R. A. (1954). Conspectus y notas críticas sobre los géneros Americanos de "Gagrellinae". Notas del Museo de La Plata, Zoología, Universidad Nacional de Eva Perón, Buenos Aires, 17, 273-308.

Rodríguez, A. L., Townsend, V. R., Jr. y Proud, D. N. (2014). Comparative study of the microanatomy of four species of Harvestmen (Opiliones, Eupnoi). Annals of the Entomological Society of America, 107, 496-509.
Roewer, C. F. (1910). Revision der Opiliones Plagiostethi (= Opiliones Palpatores). I. Teil: Familie der Phalangiidae. (Subfamilien: Gagrellini, Liobunini, Leptobunini). Abhandlun genaus dem Gebiete der Naturwissenschaften, herausge geben vom Naturwissenschaftlichen Verein in Hamburg, 19, 1-294.

Roewer, C. F. (1923). Die Weberknechte der Erde. Systematische Bearbeitung der bisher bekannten Opiliones. Jena: Gustav Fischer.

Roewer, C. F. (1953). Neotropische Gagrellinae (Opiliones, Arachnidae). (Weitere Weberknechte XVII). Mitteilungenaus dem Zoologischen Museum in Berlin, 29, 180-265.

Shear, O. A. (2004). Description of the female of Acropsopilio chomulae (Goodnight and Goodnight 1948) from Chiapas, Mexico (Opiliones, Caddidae, Acropsopilioninae). Journal of Arachnology, 32, 432-435.

Shear, O. A. (2006). Martensolas majocheni, a new genus and species of harvestman from Mexico (Opiliones: Nemastomatidae: Ortholasmatinae). Zootaxa, 1325, 191-198.

Shear, O. A. (2010). New species and records of Ortholasmatinae harvestmen from México, Honduras, and the western United States (Opiliones, Nemastomatidae, Ortholasmatinae). ZooKeys, 52, 9-45.

Taylor, C. K. (2009). Revision of the Australian Gagrellinae (Arachnida: Opiliones: Sclerosomatidae), with a description of a new species. Australian Journal of Entomology, 48, 217-222.

Tourinho, D. A. L. (2004). A new genus of Gagrellinae from Brazil, with a comparative study of some of the southernmost tropical and subtropical South American species (Eupnoi, Sclerosomatidae, Gagrellinae). Revista Ibérica de Aracnología, 9, 157-177.

Tourinho, D. A. L. y Kury, A. B. (2001). Notes on Holcobonus Roewer, 1910 (Arachnida, Opiliones, Sclerosomatidae). Boletim do Museu Nacional, N.S. Zoologia, Rio de Janeiro, 461, 1-22.

Tourinho, D. A. L. y Kury, A. B. (2003). A review of Jussara, with descriptions of six new species (Arachnida, Opiliones, Sclerosomatidae) from Brazil. Tropical Zoology, 16, 209-275. 